\title{
Inducer-Free Cellulase Production System Based on the Constitutive Expression of Mutated Xyr1 and Ace3 in the Industrial Fungus Trichoderma Reesei
}

Toshiharu Arai

Biological Science Research, Kao Corporation

\section{Sakurako Ichinose}

Biological Science Research, Kao Corporation

Nozomu Shibata

Biological Science Research, Kao Corporation

Hiroshi Kakeshita ( $\nabla$ kakeshita.hiroshi@kao.com )

Biological Science Research, Kao Corporation

Hiroshi Kodama

Biological Science Research, Kao Corporation

Kazuaki Igarashi

Biological Science Research, Kao Corporation

Yasushi Takimura

Biological Science Research, Kao Corporation

\section{Research Article}

Keywords: cellulase, enzyme, Trichoderma reesei, glucose, inducer-free, transcription factor, Xyr1, Ace3, cellulosic ethanol, biorefinery

Posted Date: December 29th, 2021

DOI: https://doi.org/10.21203/rs.3.rs-1200930/v1

License: (1) (i) This work is licensed under a Creative Commons Attribution 4.0 International License. Read Full License 


\section{Abstract}

Background: Trichoderma reesei (Hypocrea jecorina) is a filamentous fungus that can produce extremely high levels of protein; consequently, it is utilized as a host for the production of cellulase and hemicellulase cocktails for lignocellulosic biomass degradation. Several hyper-producer strains of $T$. reesei have been bred for use in industrial production, but they generally require inducers to achieve high production capacities. The most commonly used inducers are soluble sugars produced by the degradation of cellulose; however, the dependence on cellulose degradation is problematic because cellulose is insoluble and has poor handling properties as a carbon source. Furthermore, once cellulose is decomposed, little cellulase is produced, making it difficult to produce the enzyme continuously and efficiently. The aim of this study was to establish a simple, inducer-free, cellulase production system using glucose as the sole carbon source.

Results: Here, we focused on transcription factors that regulate both cellulase and hemicellulase genes. First, we verified that the previously reported Xylanase regulator 1 (Xyr1) mutation had a glucose-blind phenotype in T. reesei, and confirmed that constitutive expression of the V821F mutation in Xyr1 produced high levels of proteins, especially hemicellulase and cellulase, even in inducer-free conditions. However, the majority of proteins were hemicellulases. To reproduce cellulase/hemicellulase production similar to those observed under induced conditions, an activator of cellulase expression 3 (Ace3) was expressed in Xyr $1^{\mathrm{V} 821 \mathrm{~F}}$ expressed strain additionally. As a result, the $T$. reesei strain constitutively expressing $\mathrm{Xyr} 1^{\mathrm{V} 821 \mathrm{~F}}$ and Ace3 exhibited a 1.5 -fold increase than $\mathrm{Xyr}{ }^{\mathrm{V} 821 \mathrm{~F}}$ expressed only in protein productivity under inducer-free conditions. Notably, the enzyme composition significantly improved for cellulases ratio and similar to that induced by cellulose. Furthermore, the enzymes exhibited a high saccharification efficiency when compared to that of produced by the strain expressing only the mutated Xyr1.

Conclusions: This work shows that the constitutive expression of mutated Xyr1 and Ace 3 can increase cellulase and hemicellulase production in $T$. reesei without inducers. This inducer-free enzyme production method could provide an effective system to reduce costs and simplify production processes, and is expected to be applied in the production of various proteins.

\section{Background}

Technologies to utilize lignocellulosic biomass are expected to help produce sustainable fuels and chemicals in the future $[1,2]$ as there are large reserves already in existence and their use will not compete with food production. Lignocellulose can be converted into various material by fermentation, but first, the saccharification process is required to obtain sugar as basic raw material by enzymes. However, this can prove difficult as the saccharification of lignocellulose is different from the enzymatic saccharification of starch-based resources. Lignocellulosic biomass has a complex structure; it is cellulose and surrounded by hemicellulose and lignin, thus both cellulases and hemicellulases are required for efficient biomass 
degradation [3]. Furthermore, to achieve inexpensive degradation to monosaccharides, the required enzymes need to be produced at a low cost.

The most widely used enzymes for saccharification are produced by filamentous fungi. In particular, Trichoderma reesei (Hypocrea jecorina) secretes large amounts of several cellulases and hemicellulases into its culture supernatant [4]. For industrial use, several rounds of mutagenesis have been carried out to improve enzyme productivity and the availability of glucose as an inexpensive and general carbon source. The Rut-C30 strain [5], one of the most well-known hyper-producer of cellulase, was bred from wild-type T. reesei QM6a and is currently used for research and industrial applications worldwide. Another breeding line, QM9414 (ATCC26921), derived from the QM6a strain, also showed high enzyme productivity, and by repeating several rounds of mutagenesis, the cellulase hyper-producing mutant PC-37 strain [6-8] was obtained. Both the RUT-C30 and PC-3-7 strains contain mutations in the cre1, encoding transcription factor Cre1 $[8,9]$. Cre1 is one of the main regulators of carbon catabolite repression (CCR) [9-12]. When T. reesei is cultivated in a medium containing glucose, Cre1 represses cellulase and hemicellulase gene expression, resulting in little cellulase production. Mutations in Cre1 and other mutations in the mutagenesis process have partially de-repressed the CCR and greatly improved the enzyme productivity.

On the other hand, a disadvantage of the saccharification enzymes produced by $T$. reesei, including strain PC-3-7, is the lower activity of $\beta$-glucosidase (BGL) compared to that of other cellulase-producing microorganisms. Therefore, recombinant strains of $T$. reesei PC-3-7 expressing BGL from Aspergillus aculeatus (AaBGL1) [13] were developed. The enzyme produced by the E1AB1 T. reesei strain [14], which expresses AaBGL1 in the eg/1 promoter, enhances the degradation of $\mathrm{NaOH}$-pretreated rice straw, thereby reducing the amount of required cellulase. Interestingly, the E1AB1 strain not only exhibited improved saccharification activity but also enhanced protein secretion; this was reportedly caused by the disruption of the alpha-tubulin gene [15] and the insertion of $a a b g / 1$ in the tubulin gene locus. Furthermore, it was found that $\triangle t u b B$ acquired a phenotype that reduced CCR even in the presence of high concentrations of glucose. Therefore, owing to the transformation of $A a B G L 1$ and the effects of $\triangle t u b B$, the E1AB1 strain showed higher saccharification activity and higher enzyme productivity than that of the PC-3-7 strain. However, the high levels of enzyme productivity by E1AB1, PC-3-7, and T. reesei strains that are not modified for inducer-free production can only be shown via induction [16]. Microcrystalline cellulose is frequently used for the induction of cellulase/hemicellulase production, but it has disadvantages such as high cost, insolubility, and poor handleability (soaring during preparation and clogging of pipes) as a carbon source. In contrast, sugars such as lactose, cellobiose, sophorose, gentiobiose, and sorbose are known soluble inducers [16-19], but they are more expensive and more difficult to obtain than cellulose. Furthermore, in recent years, a process for synthesizing inducers from glucose has been developed [20], but it can become complicated because the number of enzyme production steps increases.

For industrial enzyme production, it is desirable for a production system to use only inexpensive soluble sugars such as glucose. However, glucose represses protein production due to CCR and it lacks a 
cellulase/hemicellulase inducing property. As well as the tubB mutation, the E1AB1 strain already contains direct CCR reduction because of mutations in cre 1 [8]; and mutations in bg/2 (intracellular $\beta$ glucosidase II :BGLII/Cel1a) [7], $\beta$-glucosidase-specific regulator bg/r [21], and other genes indirectly reduce CCR or enhance cellulase transcription. Even in the hyper-producer E1AB1, high expression of the cellulase gene is not observed in the absence of the inducer. In addition to $c r e 1$ and $t u b B$, there are various other repressors such as ace 1 [22], rce1 [23], rxe1 [24], and ctf1 [25], and their disruption can enhance cellulase/hemicellulase production in the induced condition. Disrupting these repressors is an important factor in inducer-free production, but disrupting these repressors alone may not be sufficient to achieve high levels of cellulase and hemicellulase. Therefore, the effect of these repressors should be eliminated; however, it is not entirely sufficient to develop an enzyme production system that uses only glucose as a carbon source. We used two approaches to further disruption the repressor to prevent CCR and artificially expression of positive regulators to improve constitutive activation of cellulase/hemicellulase, mimicking the enzyme inducing state.

Xyr1 is a major transcription factor that controls all the cellulase/hemicellulase genes in T. reesei [26]. It has a Zn (II)2Cys6 type DNA binding domain and binds directly to the upstream area of various cellulase/hemicellulase genes. Disruption of $x y r 1$ results in a cellulase-negative phenotype [26-28], indicating it is an essential factor for cellulase induction. Although the constitutive expression of $x y r 1$ in the inducing condition leads to the increased expression of cellulases/hemicellulases [26], fermentation with glucose as the sole carbon source and the constitutive expression of $x y r 1$ did not increase cellulase production in a RUT-C30-derived industrial strain [29].

Interestingly, a previous study reported that an A824V mutation of the acidic activation domain (AAD) in Xyr1 resulted in a glucose-blind phenotype [30] and a significant increase in the expression of xylanases and the basal level of cellulase transcription, even under non-inducing conditions when glucose was the sole carbon source. Furthermore, the constitutive expression of the V821F mutated Xyr1 [31][32] (corresponding to the $\mathrm{V} 756 \mathrm{~F}$ mutation in $A$. niger $\mathrm{X} \operatorname{lnR}$ [33]) showed a similar effect, and protein production was significantly increased when using non-inducible glucose or sucrose. Therefore, for hemicellulase, we hypothesized that the constitutive expression of hemicellulase genes could be achieved by mutating the acidic activation domain of the C-terminus of Xyr1, and hemicellulase production would be possible even in inducer-free conditions.

However, the expression of cellulases derived from the Xyr1 mutation was not sufficient; possibly because the enzymes produced had a low cellulase composition and thus could not efficiently decompose lignocellulose. Therefore, to produce cellulases/hemicellulases at levels similar to those in the induced conditions, it was necessary to add a cellulase activator that works in cooperation with Xyr1.

Previous studies have identified various factors associated with cellulase transcription, such as Ace2 $[34,35]$ and Ace3 [36,37], which are known as activators that directly bind to the upstream region of cellulase genes. In particular, Ace 3 is an essential transcription factor for cellulase production and is known to cross-regulate with Xyr1 [37]; consequently, the relationship between Xyr1 and Ace3 is expected 
to be important. The cellulose response transporter Crt1 [38-40] is also essential for cellulase production, and Ace 3 has been shown to bind directly to the upstream area of $c r t 1$, suggesting that Xyr1, Ace3, and Crt1 are interrelated [37]. Transcription factor Vib1 is also essential for cellulase production [41-44] and, although its exact mechanism has not yet been elucidated, it may act as an important regulator involved in cellulase induction as observed in Neurospora crassa [43]. All of these factors have positive roles in the regulatory network of cellulase biosynthesis, but their exact mechanisms as they relate to the regulation of cellulase genes and which factors trigger cellulase expression, are currently unclear.

In this study, we aimed to construct an inducer-free enzyme production system by further disrupting repressors and genetically expressing the various factors associated with cellulase transcription in the industrial E1AB1 strain, a highly productive, glucose-tolerant, and high-performance enzyme producing strain of $T$. reesei. Utilizing the desirable features of the mutated Xyr 1 , which can lead to the production of high levels of protein in non-inducing conditions, as a basal technology, we attempted to further enhance the transcriptional activation of cellulase through co-expression of the candidate factors mentioned, eliminating the disadvantage of insufficient cellulase induction. The development of strains producing cellulases without inducers will enable the construction of an inexpensive saccharification enzyme production process.

\section{Results}

\section{Effects of the disruption of repressors and the constitutive expression of V821F mutated Xyr1}

The parental strain was the high-producing cellulase strain T. reesei E1AB1 [14], and the strains generated in this study are listed in Table 1.

\section{Table 1 Trichoderma reesei strains used in this study}




\begin{tabular}{|c|c|c|}
\hline Strains & Genotypes & Parents \\
\hline PC-3-7 & Wild-type & - \\
\hline $\mathrm{E} 1 \mathrm{AB} 1$ & $a m d S^{+}$, Peg 1-aabg1 & PC-3-7 \\
\hline $\mathrm{E} 1 \mathrm{AB} 1-\Delta p y r 4$ & amdS $S^{+}$Peg1-aabg1, $\Delta$ pyr4 & $\mathrm{E} 1 \mathrm{AB} 1$ \\
\hline E1AB1-da & amd $S^{+}, \mathrm{Peg} 1-\mathrm{aabg} 1, \Delta a c e 1$ & $\mathrm{E} 1 \mathrm{AB} 1-\Delta p y r 4$ \\
\hline E1AB1-dr & amdS ${ }^{+}, \mathrm{Peg} 1-\operatorname{aabg} 1, \Delta \mathrm{rce} 1$ & $\mathrm{E} 1 \mathrm{AB} 1-\Delta p y r 4$ \\
\hline E1AB1-daX821F & amdS ${ }^{+}$, Peg1-aabg1, $\Delta$ ace1::Pact1-xyr1 (V821F) & $\mathrm{E} 1 \mathrm{AB} 1-\Delta p y r 4$ \\
\hline E1AB1-daX821F-dr & amdS ${ }^{+}, \mathrm{Peg} 1-\mathrm{aabg} 1, \Delta$ ace1::Pact1-xyr1 (V821F), $\Delta r c e 1$ & $\mathrm{E} 1 \mathrm{AB} 1-\Delta p y r 4$ \\
\hline $\begin{array}{l}\text { E1AB1-daX821F- } \\
\Delta p y r 4\end{array}$ & amdS $S^{+}$Peg1-aabg1, $\Delta$ ace1::Pact1-xyr1 (V821F), $\Delta$ pyr4 & $\begin{array}{l}\text { E1AB1- } \\
\text { daX821F }\end{array}$ \\
\hline E1AB1-daX821F-drC & $\begin{array}{l}\text { amdS }{ }^{+}, \text {Peg1-aabg1, } \Delta \text { ace 1::Pact1-xyr1 (V821F), } \\
\Delta \text { rce1::Pact1-crt1 }\end{array}$ & $\begin{array}{l}\text { E1AB1- } \\
\text { daX821F- } \Delta p y r 4\end{array}$ \\
\hline E1AB1-daX821F-drB & $\begin{array}{l}\text { amdS } S^{+}, \text {Peg1-aabg1, } \Delta a c e 1:: P a c t 1-x y r 1 \text { (V821F), } \\
\Delta r c e 1:: \text { Pact1-bglr }\end{array}$ & $\begin{array}{l}\text { E1AB1- } \\
\text { daX821F- } \Delta p y r 4\end{array}$ \\
\hline E1AB1-daX821F-drV & $\begin{array}{l}\text { amdS }{ }^{+}, \text {Peg1-aabg1, } \Delta a c e 1:: P a c t 1-x y r 1 \text { (V821F), } \\
\Delta r c e 1:: \text { Pact1-vib1 }\end{array}$ & $\begin{array}{l}\text { E1AB1- } \\
\text { daX821F- } \Delta p y r 4\end{array}$ \\
\hline E1AB1-daX821F-drA2 & $\begin{array}{l}\text { amdS }{ }^{+}, \text {Peg1-aabg1, } \Delta a c e 1:: P a c t 1-x y r 1 \text { (V821F), } \\
\text { Arce1::Pact1-ace2 }\end{array}$ & $\begin{array}{l}\text { E1AB1- } \\
\text { daX821F- } \Delta p y r 4\end{array}$ \\
\hline E1AB1-daX821F-drA3 & $\begin{array}{l}\text { amdS }{ }^{+}, \text {Peg1-aabg1, } \Delta a c e 1:: P a c t 1-x y r 1 \text { (V821F), } \\
\Delta r c e 1:: \text { Pact1-ace3 (nominal) }\end{array}$ & $\begin{array}{l}\text { E1AB1- } \\
\text { daX821F- } \Delta p y r 4\end{array}$ \\
\hline $\begin{array}{l}\text { E1AB1-daX821F- } \\
\text { drA3(complete) }\end{array}$ & $\begin{array}{l}\text { amdS }{ }^{+}, \text {Peg1-aabg1, } \Delta a c e 1:: P a c t 1-x y r 1 \text { (V821F), } \\
\text { Arce1::Pact1-ace3 (complete) }\end{array}$ & $\begin{array}{l}\text { E1AB1- } \\
\text { daX821F- } \Delta p y r 4\end{array}$ \\
\hline E1AB1-nhA3 & $a m d S^{+}$, Peg 1-aabg1, Pact1-ace3 (nominal) & E1AB1- $\Delta p y r 4$ \\
\hline E1AB1-nhA3- $\Delta p y r 4$ & amdS $S^{+}$Peg1-aabg1, Pact1-ace3 (nominal), $\Delta p y r 4$ & E1AB1-nhA3 \\
\hline E1AB1-nhX821F-nhA3 & $\begin{array}{l}\text { amdS } S^{+}, \text {Peg1-aabg1, Pact1-xyr1 (V821F), Pact1- } \\
\text { ace3 (nominal) }\end{array}$ & $\begin{array}{l}\text { E1AB1-nhA3- } \\
\Delta p y r 4\end{array}$ \\
\hline E1AB1-nhX824V-nhA3 & $\begin{array}{l}\text { amdS } S^{+} \text {Peg1-aabg1, Pact1-xyr1 (A824V), Pact1- } \\
\text { ace3 (nominal) }\end{array}$ & $\begin{array}{l}\text { E1AB1-nhA3- } \\
\Delta p y r 4\end{array}$ \\
\hline E1AB1-nhXWT-nhA3 & $\begin{array}{l}\text { amdS } S^{+}, \text {Peg 1-aabg1, Pact1-xyr1 (WT), Pact1- } \\
\text { ace3 (nominal) }\end{array}$ & $\begin{array}{l}\text { E1AB1-nhA3- } \\
\Delta p y r 4\end{array}$ \\
\hline E1AB1-drA3 & amdS', Peg1-aabg1, $\Delta r c e 1::$ Pact1-ace3 (nominal) & $\mathrm{E} 1 \mathrm{AB} 1-\Delta p y r 4$ \\
\hline
\end{tabular}


For inducer-free enzyme production, we initially confirmed the effects of the disruption of the repressors and the constitutive expression of the Xyr1 mutation. To do this, we evaluated two repressors, ace1 [22] and rce1 [23], as it has previously been reported that cellulase transcription is increased by the disruption of these repressor genes. The ace 1 or rce1 disrupted strains were generated and cultivated in shake flasks on a non-inducing medium containing $3 \%$ glucose. However, in cellulase non-inducing conditions when glucose was used as a carbon source, protein productivity after $120 \mathrm{~h}$ was extremely low for the $\mathrm{E} 1 \mathrm{AB} 1, \Delta a c e 1$, and $\Delta r c e 1$ strains $(0.40,0.55$, and $0.44 \mathrm{~g} / \mathrm{L}$, respectively) when compared to that of inducing conditions with cellulose (5.55 g/L; Fig. 1a). Furthermore, cellulases/hemicellulases were not detected in the culture supernatant (Fig. 1b, lane 2-4).

We then constructed a strain with mutated Xyr1 (V821F) that was constitutively expressed using the constitutive promoter act 1 in the ace 1 locus (named E1AB1-daX821F strain). This new mutant strain showed a significant increase in extracellular protein production under non-inducing conditions (maximum $2.08 \mathrm{~g} / \mathrm{L}$ at $96 \mathrm{~h}$; Fig. 1a), and sodium dodecyl sulfate-polyacrylamide gel electrophoresis (SDS-PAGE) showed distinct bands (Fig. 1b, closed arrowheads). Based on the estimated molecular weights, the protein bands likely corresponded to the main xylanases (XYN1, XYN2) and $\beta$-xylosidase (BXL1; Fig. 1b, lane 5), as was previously reported [14]; however, the composition was different from that of proteins produced by the parental strain E1AB1 in inducing condition (Fig. 1b, lanes 1 and 5). As shown by these results, hemicellulases were produced sufficiently but cellulases, such as $\mathrm{CBH} 1$, were not. Further rce1 gene disruption to the E1AB1-daX821F strain resulted in increased protein production (Fig. 1a), but no significant changes in the enzyme composition compared with the original E1AB1-daX821F strain (Fig. 1b, lane 6). Since the effect of repressor disruption to productivity was confirmed, subsequent constitutive expression of the transcription factors in E1AB1-daX821F was verified using the rce1 gene locus.

\section{Co-expression of various factors related to cellulase transcription in the E1AB1-daX821F strain}

The enzymes produced by the E1AB1-daX821F strain under non-inducing conditions were mostly hemicellulases; hence, we examined a combination of transcription factors that were co-expressed to enhance cellulase production. Candidates known as cellulase activators or transcriptionally essential factors, including Crt1, BglR, Vib1, Ace2, and Ace3, were constitutively expressed using the act1 promoter by homologous recombination of $r c e 1$ locus in the E1AB1-daX821F strain.

Constitutive expression of Crt1, BgIR, Vib1, and Ace2 in E1AB1-daX821F resulted in no significant changes in protein production (Fig. 2a) and enzyme composition (Fig. 2b, lanes 2-5). In contrast, the strains with constitutively expressed Ace3 showed a 1.5-fold increase in protein production when compared to E1AB1-daX821F (Fig. 2a). The enzyme composition analysis revealed that the band ratios that corresponded to hemicellulases (XYN1, XYN2, and BXL1) decreased and those corresponding to cellulases ( $\mathrm{CBH} 1, \mathrm{CBH} 2$, and EG1) increased (Fig. 2b, lane 6). The culture supernatant of the Ace3 constitutively expressed strain (named E1AB1-daX821F-drA3) showed a 4.9-fold higher pNPLase (CBH1 activity) and a 5.5-fold higher pNPGase (BGL activity) activities when compared with the E1AB1-daX821F 
strain. The eg/1 promoter has been used to express $\beta$-glucosidase AaBGL1 derived from A. aculeatus in the E1AB1 strain, suggesting that the increase in PNPGase activity reflects improved transcription of eg/1. Cellulase activities (pNPGase and pNPLase) was improved, but the changes in hemicellulase activities (pNPXase and pNPX2ase) relative to that of the E1AB1-daX821F strain were minor (1.8- and 0.8-fold, respectively). Consequently, it was considered that Ace 3 is the main contributor to the specific improvements in cellulase expression. In addition, the unknown protein band observed under noninducible conditions (Fig. 1b, lanes 2-4 with open arrowhead) was disappeared in the supernatant of Ace3 constitutive expression strain. Thus, it is inferred that cellulases are induced in the E1AB1-daX821F-drA3 strain even in the absence of inducers, and the strain resemble the state in which cellulases are inductively produced.

Consequently, we found that the E1AB1-daX821F-drA3 strain, which combines the constitutive expression of the V821F Xyr1 mutation and Ace3, makes it possible to produce not only hemicellulases but also large amounts of cellulases, even under inducer-free conditions.

\section{Confirmation of the genetic combinations required for high cellulase production under inducer-free conditions}

As described above, it was revealed that the E1AB1-daX821F-drA3 strain exhibited high cellulase production without inducers, but the strain had multiple genetic modifications: two repressor disruptions (ace1 and rce1) and constitutive expression of the V821F mutated Xyr1 and Ace3. Therefore, we confirmed whether the repressor disruption was essential and whether the effectiveness of Xyr1 was specific to the V821F mutation or not. For co-expressed Ace3, the amino acid sequence of Ace3 used in above study was referenced from the JGI genome database (http://genome.jgi.doe.gov/Trire 2/Trire 2.home.html) (651 or 629 amino acids), but this sequence was proposed to be wrong and the correct translation initiation site and intron were different; actually it was proposed that the complete sequence is 734 amino acids [37]. Consequently, both putative translation initiation sites were cloned from genomic DNA and the constitutive expression of the nominal and complete Ace3 were examined (Fig. 3a).

First, we performed constitutive expression of $\mathrm{Xyr} 1^{\mathrm{V} 821 \mathrm{~F}}$ and nominal Ace3 using non-homologous recombination (E1AB1-nhX821F-nhA3 strain). The protein productivity of the E1AB1-nhX821F-nhA3 strain of the two undisrupted repressors $(a c e 1, r c e 1)$ was lower $(2.48 \mathrm{~g} / \mathrm{L})$ than that of the E1AB1-daX821F-drA3 strain $(3.17 \mathrm{~g} / \mathrm{L})$ but higher than that of the E1AB1-daX821F strain $(2.08 \mathrm{~g} / \mathrm{L} ; \mathrm{Fig}$. 3b). Enzymes produced by the E1AB1-nhX821F-nhA3 strain showed a decrease in the composition of hemicellulase and an increase in the composition of cellulase (Fig. 3c lane 3). In other words, disruptions of ace 1 and rce 1 are not essential for the inducer-free production of cellulases, but the disruption of these repressors contributes to the alleviation of inhibition and enables efficient protein production.

We also examined whether cellulases could be efficiently produced only by the constitutive expression of nominal Ace3 without V821F mutated Xyr1 (E1AB1-nhA3 strain). The intensity of protein bands corresponding to cellulases was increased (Fig. 3c, lane 4), indicating that cellulases could be slightly 
induced with the constitutive expression of nominal Ace3 under non-inducible conditions. However, protein bands corresponding to hemicellulases were not observed following SDS-PAGE, and the total protein concentration was significantly lower when compared to that of the E1AB1-daX821F strain (Fig. $3 b)$. This suggests that the constitutive expression of nominal Ace3 alone did not affect protein productivity and hemicellulase production, but slightly affected cellulase production.

Furthermore, when the constitutive expression of wild-type Xyr1 was introduced in the nominal Ace3 expressed strain (E1AB1-nhXWT-nhA3 strain), the protein concentration and SDS-PAGE band pattern (Fig. 3b: $0.51 \mathrm{~g} / \mathrm{L}$; Fig. 3c lane 5) showed almost the same phenotype as the strain of the nominal Ace3 alone (E1AB1-nhA3 strain) (Fig. 3b: 0.61 g/L; Fig. 3c lane 4). In other words, Co-expression of wild-type Xyr1 and Ace3 did not have no effect on protein production in non-inducing condition, so the effective mutation of Xyr1 such as V821F was essential for inducer free production.

We then confirmed whether the V821F mutated Xyr1 was the specific effective mutant or not. In addition to V821F, the A824V mutation was also previously identified as an effective mutation [30], so a strain coexpressed A824V mutated Xyr1 and Ace3 (E1AB1-nhX824V-nhA3 strain) was constructed and the protein productivity and its composition of the produced enzyme was evaluated (Fig. 3a). The protein productivity of the A824V mutation co-expressed strain $(2.17 \mathrm{~g} / \mathrm{L})$ was significantly higher than that of Ace3 alone $(0.61 \mathrm{~g} / \mathrm{L})$ or when co-expressed with Xyr1 ${ }^{\mathrm{WT}}(0.51 \mathrm{~g} / \mathrm{L}$; Fig. 3a and 3d), but the productivity tended to be lower than that of V821F $(2.54 \mathrm{~g} / \mathrm{L} ; p=0.07)$. The enzyme composition of E1AB1-nhX824VnhA3 strain was mainly composed of cellulase and this was similar to that of E1AB1-nhX821F-nhA3 strain, so the mutation of A824V and V821F in Xyr1 seemed to be almost the same effect on inducer free production. However, when $\mathrm{Xyr} \mathrm{A}^{\mathrm{A} 824 \mathrm{~V}}$ was used, the band intensities for the hemicellulases (BXL1, XYN1, and XYN2) were slightly decreased compared to those when Xyr ${ }^{\mathrm{V} 821 \mathrm{~F}}$ was used. Therefore, although there may be slight differences in protein production and hemicellulase expression, in this system it is important to co-express Ace 3 and Xyr1, which are effective glucose-blind phenotypes, and the effect is not unique to the V821F mutation.

The nominal and complete Ace3 sequences were then examined (Fig. 3a). Improvement in cellulase production was also confirmed in the complete Ace3, but protein productivity of $\mathrm{Xyr}^{\mathrm{V} 821 \mathrm{~F}}$-complete Ace3 decreased by $14 \%$ and the cellulase band intensity also decreased compared with that of the $\mathrm{Xyr} 1^{\mathrm{V} 821 \mathrm{~F}}$. nominal Ace3 (Fig. 3d, 3e lanes 3,4). Thus, it was concluded that it is not necessary to have the complete $\mathrm{N}$-terminal sequence for inducer-free production; partial truncation of the DNA-binding domain of Ace3 is preferable.

These results demonstrated that although the disruption of the ace 1 and $r c e 1$ repressors was not essential for inducer-free production, it was preferable for productivity. As for the transcriptional activators, it is effective to constitutively express both the mutated Xyr 1 exhibiting a glucose-blind phenotype (V821F, A824V, and so on, but not the wild-type) and the DNA-binding domain truncated nominal Ace3. 


\section{Analysis of gene expression and produced enzymes}

We evaluated the comparative transcription level ( $\triangle \Delta$ Ct method using $p g k 1$ gene as a normalizer and E1AB1-daX821F strain as calibrator) of the major saccharifying enzyme genes after $48 \mathrm{~h}$ of glucose culturing. In the E1AB1-daX821 F-drA3 strain, the transcription level of the major cellulases $c b h 1$, $c b h 2$, and eg/1, increased to the level of that of the E1AB1-daX821F strain, but the increase in expression of the major hemicellulases $x y n 1, x y n 2$, and $b x / 1$ were a maximum of 1.7-fold (Fig. 4a), which is in agreement with the aforementioned enzymatic activity (Fig. 2c). These gene expression results also suggested that Ace 3 is a cellulase-specific transcription factor. Owing to the effect of the Xyr 1 mutation, the transcription of major cellulases in the E1AB1-daX821F strain was approximately four orders of magnitude higher than that of the parent strain E1AB1 (relative $c b h 1$ expression level: 0.00013), but it was possible to further increase the transcription level of the cellulases by the constitutive expression of the nominal Ace3 (6.4-fold).

Consistent with the gene expression analysis results, the enzymes produced by the E1AB1-daX821F-drA3 strain exhibited a similar amount of hemicellulase and a specific increase in the cellulase ( $\mathrm{CBH} 1, \mathrm{CBH} 2$, EG1) components when compared to the E1AB1-daX821F strain (Fig. 4b). The cellulase/hemicellulase composition ratio of the E1AB1-drA3 and the E1AB1-daX821F-drA3 strains in the non-induced culture using glucose was similar to that of the induced culture of the parental E1AB1 strain using cellulose (Fig. 4b; see Additional file 1). For the E1AB1-daX821F-drA3 strain, the composition ratio of the hemicellulases (XYN1, XYN2, BXL1) was relatively high, as an effect of the mutated Xyr1 phenotype. In the E1AB1-drA3 strain, the hemicellulase composition ratio and activity (pNPX2ase, pNPXase) were extremely low (see Additional file 2), and the degradative activity of pNPX2ase and pNPXase was only $0.6 \%$ and $1.5 \%$, respectively, when compared to that of the E1AB1-daX821F-drA3 strain. That is, the constitutive expression of Ace3 can activate cellulase production, but not hemicellulase; as a result, the produced enzyme cocktail contained extremely low levels of hemicellulase.

Saccharification tests on microcrystalline cellulose were conducted using enzymes produced under cellulose (induced) and glucose (inducer-free) conditions. In the evaluation using the same protein dosage, the amount of released glucose was the highest by the enzyme produced by the parental E1AB1 strain induced with cellulose (268 g-glucose/g-protein), but the enzyme produced by the E1AB1-daX821FdrA3 strain was the most superior under inducer-free conditions (225 g-glucose/g-protein; Fig. 4c). The enzymes from the E1AB1-drA3 strain also showed relatively high saccharification activity per protein (178 g-glucose/g-protein), and significantly higher saccharification activity than the enzymes derived from the E1AB1-daX821F strain (77 g-glucose/g-protein). This is estimated to be due to the high composition ratio of the cellulase components within the added protein. However, as described above, the concentrations of the enzymes produced by the E1AB1-drA3 strain were only $0.57 \mathrm{~g} / \mathrm{L}$ protein (Fig. 4b; see Additional file 3); thus, the absolute amount of the cellulase in the enzymes of E1AB-drA3 was approximately $27 \%$ of that in E1AB1-daX821F-drA3 (Fig. 4b). In contrast, the enzyme cocktail derived from the E1AB1-daX821F strain contained a high protein concentration, but its composition was mainly hemicellulases; as a result, the absolute amount of cellulases was equivalent to that of the E1AB1-drA3 and E1AB1-daX821F strains 
(Fig. 4b) and significantly lower than that of the E1AB1-daX821F-drA3 strain. Therefore, when saccharification was performed with the same volume $(0.87 \mathrm{~mL}$ culture supernatant/g cellulose: approximately $2.0 \mathrm{mg}$ E1AB1-daX821F-drA3 strain derived protein/g cellulose), the enzymes derived from the E1AB1-daX821F and E1AB1-drA3 strains showed almost the same amount of released glucose (6.5 and $7.5 \mathrm{~g} / \mathrm{L}$ glucose), significantly lower than that of the E1 AB1-daX821F-drA3 strain (19.9 g/L glucose; Fig. 4d). As a result, the E1AB1-daX821F-drA3 strain was considered superior to that of the existing inducer-free $\mathrm{Xyr}{ }^{\mathrm{V} 821 \mathrm{~F}}$ overexpressed strain.

From the above, the E1AB1-daX821F-drA3 strain was found to have two combined important phenotypes: increased cellulase composition ratio by constitutive expression of Ace3 and high protein productivity under non-inducing conditions by the introduction of mutated Xyr1. We achieved the most important and essential property of the cellulolytic enzyme, the high production of cellulase in a non-inducing production system.

\section{Discussion}

The E1AB1 strain shows higher saccharification activity and higher enzyme productivity than the hyperproducing PC-3-7 strain [15], but the desirable characteristics are only available under induced conditions. Thus, we aimed to construct an inexpensive inducer-free enzyme production system by disrupting the repressors and genetically expressing various factors associated with cellulase transcription in the industrial E1AB1strain. We succeeded in creating an E1AB1-based strain that produces high levels of cellulases and hemicellulases without inducers by constitutively expressing effective mutated Xyr1 and Ace3. This demonstrated that these two factors are required to improve the production of cellulase using a production system with glucose as the sole carbon source.

One of the factors, Xyr1, has previously been studied as an important regulatory factor, but its detailed regulatory mechanisms are still unclear. Xyr1 is known to be suppressed by catabolite repression, but constitutive expression by promoter modification does not show the same cellulase expression as when induced by cellulose in RUT-C30-derived strain [29]. That is, the expression of the cellulase/hemicellulase genes was not regulated only by the transcription of Xyr1, suggesting that there is a regulation that occurs only in the presence of the inducer. In contrast, only the overexpression of Xyr1 by the copperrepressible promoter Ptcu1 in a T. reesei QM9414 strain resulted in the high-level production of cellulase on glucose [45]. Further research is required because the degree of the mutation of CCR-related factors and activator/repressors is different in the ancestral lines.

Mutations to the acidic activation domain of Xyr1, e.g., A824V [30] or V821F [31,32], are important for the regulation of cellulase/hemicellulase transcription and may mimic some of the changes in Xyr1 caused by inducers. This type of effective mutation, however, does not completely reproduce the induction by cellulose; Xyr1 is mainly transcriptional activation of hemicellulases [31,32] (Fig. 1b). This effect is similar to the constant expression of xylanase under non-inducing conditions with the V756F mutation in $\mathrm{X} \operatorname{lnR}$ of $A$. niger [33], and it is inferred that Xyr1 has a similar function as a homolog of XInR. However, 
Xyr1 in $T$. reesei differs from XInR in that it is involved not only in xylanase, but also cellulase, transcriptional regulation. Here, we focused on the important aspect that introducing effective mutations in Xyr 1 could achieve high protein productivity without inducers, although mainly hemicellulases would be affected, and it was expected that genes under the control of Xyr1 (potentially, hundreds of genes [46], e.g., the secretory system) would also be activated. Therefore, basal transcription of hemicellulase genes and the production of high protein levels could be accomplished by the Xyr1 mutation. Furthermore, it was considered important to combine the factors that control upregulation of cellulase genes.

The other factor, Ace3, has been shown to play an important role in the reports of factors that are involved in cellulase regulation. Ace3 [36] is a transcription factor that has a DNA-binding domain-like Xyr1, and the disruption of Ace3 results in the disappearance of cellulase expression and the reduction of xylanase expression, even under inducing conditions [36], indicating that it is an essential factor for cellulase expression. Furthermore, it was of interest that a heterodimer was formed with the C-terminal region of Ace3 and the acidic activation domain of Xyr1 [37]. The domain was located at the important mutation sites such as A824V and V821F. The interaction between these two essential transcription factors at the $\mathrm{C}$-terminus is likely to play an important role in the regulation of cellulase induction.

In addition, Ace3 of $T$. reesei NG14 and the derived RUT-C30 and RL-P37 [47] strain contain an 11 amino acid truncation at the $\mathrm{C}$-terminus, thereby improving cellulase production [48]. Furthermore, overexpression of Ace3 with the appropriate C-terminal truncation of 7-17 amino acids could confer enhanced protein production under both non-inducing and inducing conditions [49]. Luo et al. (2020) reported cellulase production under inducer-free conditions by utilizing this effective $\mathrm{C}$-terminal truncation of Ace3; in this system, the Zn2Cys6 DNA-binding domain with all 6 cysteines at the N-terminus and the 11-amino acid C-terminal truncation are both required and sufficient to enable high protein secretion under non-inducing conditions [49]. However, in our system, the constitutive expression of Ace3 without a C-terminus mutation was used in combination with mutated Xyr1 to achieve protein production under inducer-free conditions. The complete DNA-binding domain in the N-terminus was not required; in fact, the production was more effective when using an incomplete DNA-binding domain (Fig. 3d). Transcript analysis of the Ace 3 showed that there were transcripts derived from the same genomic sequence at two different transcription initiation sites [49]; it was confirmed that only the transcripts of exons 3 and 4 (similar to the product of nominal Ace3 transcript) were increased by sophorose-inducing conditions [49]. Thus, the nominal Ace3 sequence region that was constitutively expressed in this study may be important for cellulase production. In addition, in the C-terminus truncation system, the co-expressing effect with $\mathrm{Xyr}^{\mathrm{A} 824 \mathrm{~V}}$ was slightly improved under the inducing condition, but there was little change under the noninducing condition [49], and the additive/synergistic effects were not confirmed. The optimal set of constitutive genes; that is, the combination of genomic and overexpressed Xyr1 (wild-type and/or glucose-blind phenotype) and Ace3 (N-terminal variation with multiple putative initiation sites and/or Cterminal mutations) needs to be examined further, but this study showed that effective inducer-free production is possible and that the C-terminal mutation of Ace 3 is not genetically essential. 
In a study using Trichoderma orientalis, the overexpression of wild-type Xyr1 and Ace3 had an improving effect on cellulase production in an inducer-free culture [50], but in our study constitutive expression of Ace3 alone or the co-expression of wild-type Xyr1 and Ace3 did not exert a sufficient effect (Fig. 3b). Although the cellulase was slightly expressed in the non-inducing conditions by the constitutive expression of Ace3 alone, its effect was weak in cellulase transcription and protein concentration (Fig. 3b, $4 a, 4 b)$. Therefore, Ace 3 is essential for cellulase transcriptional expression, but Ace 3 alone cannot cause high levels of cellulase expression as observed under inducing conditions. This suggests that the activation of cellulase can be achieved in cooperation with constitutively activated Xyr 1 , such as the A824V or V821F Xyr1 mutation. Especially in terms of protein productivity, it was extremely important to combine with the effective Xyr1 mutation. Further research is required regarding the regulatory mechanisms of Ace3 in the presence of the mutant and wild-type Xyr1.

Disruption of the ace1, rce1 repressor used for the insertion locus was not essential and did not contribute to the essence of this system (Fig. 3b, 3c). In the E1AB1 strain used in this study, CCR is thought to be dysfunctional due to the cre1 mutation [8], tubB mutation [15], and so on. It needs to be examined whether the elimination of the repressor is essential for this system in the ancestral wild-type strain.

The co-expression of $\mathrm{Xyr} \mathrm{V}^{\mathrm{V} 821 \mathrm{~F}}$ with other factors related to cellulase regulation did not have a clear effect (Fig. 2), suggesting that the increased expression of Crt1, BgIR, and Vib1 does not induce cellulase, but may contribute through signaling during fundamental cellulase induction. It is possible that enhancing the expression of Xyr1 or Ace 3 may influence the expression of these factors (e.g., Crt1 is regulated by Ace3 [37]), and analysis using our system may help to clarify the contributions of each factor.

Enzyme productivity of the E1AB1-daX821F-drA3 strain using glucose was significantly improved when compared with the parent strain and the E1AB1-drA3 strain, but slightly inferior to that of the parent E1AB1 strain using cellulose (Fig. 1a, 4b). It was considered that this is largely dependent not only on the inducibility of the carbon source but also on the properties of cellulose as a carbon source. Glucose is extremely easy to assimilate and is rapidly consumed; it was depleted after $48 \mathrm{~h}$ in this study (see Additional file 3). On the other hand, cellulose cannot be easily assimilated and may slowly decompose to release cellobiose and glucose for a long time. Thus, in the culture using cellulose, the carbon source is gradually supplied, and the production may be performed in an environment where CCR is not triggered. Even in the E1AB1-daX821F-drA3 strain, the protein was not produced under high glucose concentration conditions (see Additional file 3), so CCR has not been completely absolved and the practice of avoiding CCR (e.g., fed-batch culture [51,52]) was considered to be more effective for exhibiting potential.

The enzyme composition of the E1AB1-daX821F-drA3 strain without inducer was almost the same as that of induction with cellulose (Fig. 4b, Additional file 1), and showed higher saccharification performance to the cellulose substrate than the existing inducer-free production systems, such as E1AB1daX821F strain (Fig. 4c, 4d). The enzyme obtained by constitutive expression of the mutated Xyr1 alone 
showed mainly hemicellulases (Fig. 1b; see Additional file 1), so this enzyme is considered unsuitable for the saccharification of cellulose. It is also possible to improve cellulase expression through the constitutive expression of Ace3 alone (Fig. 3c; see Additional file 1), but defects were observed, such as low protein productivity and the extremely low activity of hemicellulases (see Additional file 2), that would show the low saccharification performance for the hemicellulose-rich substrate. That is, an inducer-free system with modified Ace3 may have a problem in the production of hemicellulases. In this study, these disadvantages were eliminated by the combination of the Xyr1 mutation and Ace3. However, the glucose releasing activity of the enzyme produced under inducer-free conditions was slightly lower than that produced by conventional induction using cellulose. This may be because the saccharification activity was dependent on the characteristic of the target substrate and optimization of the enzyme composition is needed. Also, minor enzymes (not under the control of Xyr1 and Ace3) may not be expressed; thus, detailed verification, such as a comprehensive analysis of the glycoside hydrolase family, is required in the future.

Although the present study revealed the major factors involved in the production of cellulases and hemicellulases, the regulatory mechanism remains unclear; further investigation is needed to determine how mutations in Xyr1 and partial truncation of the DNA-binding domain of Ace3 affect protein productivity and enzyme composition. Analysis of the formation of heterodimers and homodimers of wild-type/mutated Xyr1/Ace3 and DNA binding ability to specific regions may provide a clue to the regulatory mechanism. In addition, the relationship between various negative regulators, including CCR, and positive regulators remains unclear. Since the strains used in this study are well-bred industrial strains and various repressive mechanisms have been eliminated, further investigation is needed to determine the optimal gene set, including activators and repressors.

In a different application, $T$. reesei is regarded as a promising host for heterologous protein production owing to its high protein production ability $[53,54]$; however, it is difficult to use the conventional cellulosebased enzyme production system for heterologous protein production. This is because the sugars from the decomposed cellulose act as inducers, producing high levels of cellulase. If the cellulase genes are replaced with genes for the proteins of interest, cellulose cannot be decomposed, the inducer is not released, and high protein production potential will not be exhibited. On the other hand, if cellulase is not disrupted, a large amount of native cellulases will be produced. Previous reports showed heterologous protein production using $x y n 1$ and $x y n 2$ promoters with $\mathrm{Xyr}^{\mathrm{A}}{ }^{824 \mathrm{~V}}$ [55]; but from the results of this study, it has become possible to use the extremely strong cellulase promoters, such as $c b h 1$ and $c b h 2$, for heterologous protein production without the co-production of cellulase. Such strong cellulase promoters are expected to be great production tools that can be used not only for saccharifying enzymes for bioethanol production but also for the production of various valuable proteins.

\section{Conclusion}

In this study, we developed a genetic modification strategy for filamentous fungus $T$. reesei using simple glucose culture that can efficiently produce cellulases and hemicellulases without inducers by 
constitutive expression of modified Xyr1 and Ace3, which are the main regulators of cellulase/hemicellulase. Contrary to the previously reported Xyr1 system using the V821F mutation alone or the Ace3 mutation alone, the present two transcription factor combination system was able to produce both cellulase and hemicellulase in an appropriate ratio for biomass saccharification, similar to that observed under induced production. In addition, although the Ace3 DNA-binding domain has been thought to be essential for inducer-free production, we found that when co-expressed with $\mathrm{Xyr}{ }^{\mathrm{V} 821 \mathrm{~F}}$, Ace3 with partial truncation of the DNA-binding domain was more effective in terms of cellulase production. Using this inducer-free enzyme production system, it is possible to produce enzymes efficiently using glucose, which is an inexpensive and easy-to-handle carbon source, without relying on cellulose for induction. Thus, it has the potential to help reduce costs and simplify the production process. Furthermore, since the induction of enzyme production does not depend on cellulose degradation by cellulase, it is expected that the high enzyme production capacity can be applied to the production of various proteins of interest.

\section{Methods}

\section{Strains and propagation}

The $T$. reesei strains used in this investigation are listed in Table 1. T. reesei strains E1AB1 [14] and E1AB1 $\Delta$ pyr4 (uracil auxotroph) were kindly provided by Prof. W. Ogasawara (Nagaoka University of Technology). Strains were maintained on potato dextrose agar (PDA; Difco Laboratories, Detroit, MI) plates.

\section{Shake flask cultivation}

For preculture enzyme production, $4 \times 10^{5}$ spores of each strain were inoculated into $2 \mathrm{~mL}$ of basal medium [6] containing $1 \%(\mathrm{w} / \mathrm{v})$ glucose in a 10-mL culture tube. Spores were counted using a Thoma hemocytometer (Sunlead Glass Corp.). The basal medium comprised $0.14 \%(\mathrm{w} / \mathrm{v})\left(\mathrm{NH}_{4}\right)_{2} \mathrm{SO}_{4}, 0.2 \%(\mathrm{w} / \mathrm{v})$ $\mathrm{KH}_{2} \mathrm{PO}_{4}, 0.03 \%(\mathrm{w} / \mathrm{v}) \mathrm{CaCl}_{2} \cdot 2 \mathrm{H}_{2} \mathrm{O}, 0.03 \%(\mathrm{w} / \mathrm{v}) \mathrm{MgSO}_{4} 7 \mathrm{H}_{2} \mathrm{O}, 0.1 \%(\mathrm{w} / \mathrm{v})$ polypeptone, $0.05 \%(\mathrm{w} / \mathrm{v})$ yeast extract, $0.1 \%(\mathrm{w} / \mathrm{v})$ Tween 80 , and $0.1 \%(\mathrm{w} / \mathrm{v})$ trace element solution in $50 \mathrm{mM}$ Na-tartrate buffer $(\mathrm{pH} 4.0)$. The trace element solution contained $6 \mathrm{mg} \mathrm{H}_{3} \mathrm{BO}_{3}, 26 \mathrm{mg}\left(\mathrm{NH}_{4}\right)_{6} \mathrm{Mo}_{7} \mathrm{O}_{24} \cdot 4 \mathrm{H}_{2} \mathrm{O}, 100 \mathrm{mg} \mathrm{FeCl} \cdot 6 \mathrm{H}_{2} \mathrm{O}, 40$ $\mathrm{mg} \mathrm{CuSO} \mathrm{S}_{4} \cdot 5 \mathrm{H}_{2} \mathrm{O}, 8 \mathrm{mg} \mathrm{MnCl} \cdot 4 \mathrm{H}_{2} \mathrm{O}$, and $200 \mathrm{mg} \mathrm{ZnCl} 2$ in $100 \mathrm{~mL}$ of distilled water. Preculturing was carried out by shaking at $220 \mathrm{rpm}$, at $28^{\circ} \mathrm{C}$ for 2 days. For each of the main cultures, $500 \mu \mathrm{L}$ of the preculture was inoculated into $50 \mathrm{~mL}$ of basal medium containing $3 \%(\mathrm{w} / \mathrm{v})$ powdered cellulose $(\mathrm{KC}$ FLOCK W-400G, Nippon Paper Industries) or glucose and 1.28\% (w/v) diammonium hydrogen citrate in a $500 \mathrm{~mL}$ Erlenmeyer flask. The main culture was shaken at $220 \mathrm{rpm}$, at $28^{\circ} \mathrm{C}$ for $3 \sim 5$ days. For sampling, cells were removed from the culture broth by centrifugation at $16,000 \mathrm{~g}$ for $5 \mathrm{~min}$, and the supernatant was filtered through a $0.20 \mu \mathrm{m}$ cellulose acetate membrane filter (13CP020AN; Advantec, Toyo Roshi Kaisha). All experiments were carried out in triplicate.

\section{Molecular cloning and construction of the expression cassettes}


The genes of interest were amplified from the genomic DNA of T. reesei strain PC-3-7, and a vector fragment was amplified by inverse polymerase chain reaction (PCR) using pUC118 (Takara Bio) as the template. The amplified fragments, designed using primers that added a Swal cleavage site, were ligated using an In-Fusion HD Cloning Kit (Clontech) according to the manufacturer's protocol. Escherichia coli DH5a was used as a cloning host, and a NucleoSpin® Plasmid miniprep kit (Takara Bio) was used to purify the plasmid DNA. More details on the cloned gene and primers are provided in an additional file (see Additional file 4). The vector fragment pUC-K017 was generated by inverse PCR; it was derived from the ligated ace 1 inserted plasmid (pUC-K003) and pyr4 marker cassette (pUC-K016). An inverse PCR fragment of the ace1 disruption construct (pUC-K017) and fragments of the act1 promoter, $x y r 1$, and $c b h 1$ terminator was ligated to generate the plasmid $\triangle$ Ace1-Pact1-xyr1-pyr4 (pUC-K019). Using this plasmid as a template, inverse PCR was performed to mutate valine to phenylalanine at position 821 to

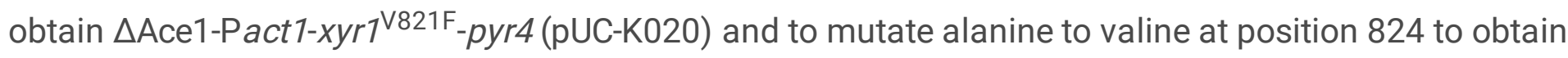
$\triangle \mathrm{Ace} 1-\mathrm{Pact1}$-xyr ${ }^{\mathrm{A} 824 \mathrm{~V}}$-pyr4 (pUC-K021). In the same manner, an inverse PCR fragment of the rce1 disruption construct (pUC-K018) and fragments of the act1 promoter, ORFs (crt1, bglr, vib1, ace2,nominal ace3, complete ace3), and the $c b h 1$ terminator were ligated to generate the plasmids pUC-K022, pUCK023, pUC-K024, pUC-K025, pUC-K026, and pUC-K027, respectively. For nominal ace3 and complete ace3, pUC-K010 was used as a template to design a forward primer based on the two types of putative initiation codons. More details on vector construction and the primers used are provided in an additional file (see Additional file 5).

\section{Transformation of $T$. reesei}

Plasmids were linearized with Swal prior to the transformation of T. reesei, or the PCR product was transformed using a modified protoplast-PEG method [56], in which $20 \mathrm{mg} / \mathrm{mL}$ of Yatalase (Takara Bio) was used as the protoplasting enzyme instead of Novozyme 234 (Novozymes Bagsværd, Denmark). The transformed protoplasts were plated on minimal transformation medium [2.0\% (w/v) glucose, $18.27 \%$ (w/v) sorbitol, $0.5 \%(\mathrm{w} / \mathrm{v})\left(\mathrm{NH}_{4}\right)_{2} \mathrm{SO}_{4}, 0.2 \%(\mathrm{w} / \mathrm{v}) \mathrm{CaCl}_{2}, 0.06 \%(\mathrm{w} / \mathrm{v}) \mathrm{MgSO}_{4}, 0.21 \%(\mathrm{w} / \mathrm{v}) \mathrm{CsCl}$, and $0.1 \%$ $(\mathrm{w} / \mathrm{v})$ trace element solution in $100 \mathrm{mM} \mathrm{KH}_{2} \mathrm{PO}_{4}$ buffer $(\mathrm{pH}$ 5.5)] for the pyr4 marker. The trace element solution contained $500 \mathrm{mg} \mathrm{FeSO} \cdot 7 \mathrm{H}_{2} \mathrm{O}, 200 \mathrm{mg} \mathrm{CoCl} 2,160 \mathrm{mg} \mathrm{MnSO}{ }_{4} \cdot \mathrm{H}_{2} \mathrm{O}$, and $140 \mathrm{mg} \mathrm{ZnSO}{ }_{4} \cdot 7 \mathrm{H}_{2} \mathrm{O}$ in $100 \mathrm{~mL}$ of distilled water. After 2 weeks of incubation at $30^{\circ} \mathrm{C}$, candidate transformants were streaked twice on selective plates (each minimal transformation medium without sorbitol) for several days at 30 ${ }^{\circ} \mathrm{C}$ for single-colony isolation. Single colonies were then transferred to PDA plates for 1 week at $30{ }^{\circ} \mathrm{C}$ to allow for the formation of conidia. One transformant was confirmed by colony PCR using KOD One (Toyobo) according to the manufacturer's protocol. To transform the resulting transformants again using PDA medium containing $0.2 \%(\mathrm{w} / \mathrm{v})$ 5-fluoroorotic acid (5-FOA) monohydrate, a strain that acquired 5FOA resistance again (pyr4 pop-out through homologous recombination) was selected.

\section{Culture supernatant and cell biomass analysis}

Protein concentration was determined using the Bradford protein assay (Bio-Rad) with bovine gamma globulin as the standard, according to the manufacturer's protocol. The glucose concentration in the 
supernatant was quantified using the Glucose CII Test Wako Kit (Wako Chemicals). Specifically, $150 \mu \mathrm{L}$ of the reaction solution was added to $1 \mu \mathrm{L}$ of the diluted supernatants in a 96-well plate, mixed well, and incubated at room temperature for $15 \mathrm{~min}$. The absorbance of all samples and standards was measured at $505 \mathrm{~nm}$ using a microplate reader (Molecular Devices).

\section{Real-time quantitative PCR (RT-qPCR) analysis}

The cell pellet, collected by centrifugation, was lightly dewatered and frozen in liquid nitrogen. A metal cone was placed in the frozen sample prior to crushing with a MULTI-BEADS SHOCKER (Yasui Kikai Corp.) at $1700 \mathrm{rpm}$ for $10 \mathrm{sec}$, and RNA extraction was subsequently performed using the RNeasy Mini Kit (Qiagen), according to the manufacturer's protocol. gDNA digestion and cDNA synthesis were performed using ezDNase ${ }^{\mathrm{TM}}$ Enzyme (Invitrogen) and SuperScript ${ }^{\mathrm{TM}}$ IV VILO $^{\mathrm{TM}}$ Master Mix (Invitrogen), respectively. RT-qPCR experiments were performed with Brilliant III Ultra-Fast SYBR Green QPCR Master Mixes (Agilent), and the transcriptional levels of $p g k 1$ and E1AB1-daX821F strain RNA were measured for reference calculation and data normalization, respectively. All samples were analyzed in at least three independent biological experiments. The primers used for real-time PCR were designed using Primer3 (https://bioinfo.ut.ee/primer3-0.4.0/) and are listed in an additional file (see Additional file 6).

\section{Enzyme composition analysis}

SDS-PAGE was carried out using Any kD Mini-PROTEAN TGX Precast Protein Gels (Bio-Rad) for 35 min at $200 \mathrm{~V}$. The gel was activated for $5 \mathrm{~min}$ and imaged using the ChemiDoc MP imaging system (Bio-Rad). Precision Plus Protein Unstained Standard ( $5 \mu \mathrm{L}$; Bio-Rad) was used as a molecular mass marker. Unless otherwise noted, $2.5 \mathrm{\mu g}$ of protein was loaded in each well. The molecular weight of the protein bands was estimated using Image Lab software (Bio-Rad), and the protein bands were annotated using the positions corresponding to previously reported cellulases and hemicellulases [14].

\section{Enzyme activity analysis}

The enzymatic activities of cellobiohydrolase, $\beta$-glucosidase, xylanase, and $\beta$-xylosidase were measured using the substrates $p$-nitrophenyl- $\beta$-D-lactoside (pNPL), $p$-nitrophenyl- $\beta$-D-glucopyranoside (pNPG), $p$ nitrophenyl- $\beta$-xylobioside (pNPX2), and $p$-nitrophenyl- $\beta$-D-xylopyranoside (pNPX), respectively. The reactions were carried out in $50 \mathrm{mM}$ sodium acetate at $\mathrm{pH} 5.0$ and $50{ }^{\circ} \mathrm{C}$ for $10 \mathrm{~min}$ and terminated by adding one volume of $1 \mathrm{M} \mathrm{Na}_{2} \mathrm{CO}_{3}$. The released $p$-nitrophenol was quantified by measuring the absorbance at $420 \mathrm{~nm}$. One unit of activity is defined as the amount of enzyme that produced $1 \mu \mathrm{mol}$ of p-nitrophenol per minute at $50^{\circ} \mathrm{C}$.

Cellulose saccharification was performed on $1 \mathrm{~mL}$ scale in 9-mL glass screw-top bottles at a loading of $5 \%(\mathrm{w} / \mathrm{v})$ microcrystalline cellulose (Avicel ${ }^{\circledR} \mathrm{PH}-101$, Sigma-Aldrich) in $100 \mathrm{mM}$ sodium acetate buffer, $\mathrm{pH} 5.0$, using an enzyme loading of $2.0 \mathrm{mg}$ protein/g cellulose. The protein concentration was determined as mentioned above. The reaction was performed at $50{ }^{\circ} \mathrm{C}$ under shaking at $150 \mathrm{rpm}$ for $72 \mathrm{~h}$. Samples obtained following saccharification were filtered $(0.2 \mu \mathrm{m})$, and the glucose concentration was measured 
using an enzymatic assay and a Multifunction Biosensor BF-7 (Oji Scientific Instruments), according to the manufacturer's protocol.

\section{Statistical analysis}

All experiments were performed with at least three independent samples. Error bars indicate the standard deviation (SD) of the mean of triplicates. Statistical significance was determined by the two-tailed unpaired Student's t-test. Within each set of experiments, $p<0.05$ was considered significant.

\section{Abbreviations}

BGL: $\beta$-glucosidase; $\mathrm{BXL}$ : $\beta$-xylosidase; $\mathrm{CBH}$ : cellobiohydrolase; CCR: carbon catabolite repression; EG: endoglucanase; PCR: polymerase chain reaction; pNPG: $p$-nitrophenyl- $\beta$-D-glucopyranoside; $\mathrm{PNPL}: p$ nitrophenyl- $\beta$-D-lactoside; pNPX: $p$-nitrophenyl- $\beta$-D-xylopyranoside; pNPX2: $p$-nitrophenyl- $\beta$-xylobiosid; $\mathrm{XYN}$ : xylanase

\section{Declarations}

\section{Ethics approval and consent to participate}

Not applicable

\section{Consent for publication}

Not applicable

\section{Availability of data and materials}

The datasets used and/or analyzed during the current study are available from the corresponding author upon reasonable request.

\section{Competing interests}

The authors declare that they have no competing interests.

\section{Funding}

Not applicable

\section{Authors' contributions}

TA, SI, HK designed the study; TA analyzed the results and drafted the manuscript; SI participated in the construction of strains and gene analysis; NS, HK, HK, KI, and YT reviewed and commented on the manuscript. All the authors read and approved the final manuscript. 
Acknowledgments

The authors thank Prof. Wataru Ogasawara from the Nagaoka University of Technology for providing the T. reesei strains. We would like to thank Editage (www.editage.com) for English language editing.

\section{References}

1. Ulber R, Sell D. White Biotechnology. Adv. Biochem. Eng. Biotechnol. 2007.

2. Srivastava N, Srivastava M, Mishra PK, Singh P, Ramteke PW. Application of Cellulases in Biofuels Industries: An Overview. J Biofuels Bioenergy. 2015;1:55.

3. Song HT, Gao Y, Yang YM, Xiao WJ, Liu SH, Xia WC, et al. Synergistic effect of cellulase and xylanase during hydrolysis of natural lignocellulosic substrates. Bioresour Technol. 2016;219:710-5.

4. Cherry JR, Fidantsef AL. Directed evolution of industrial enzymes: An update. Curr Opin Biotechnol. 2003;14:438-43.

5. MONTENECOURT BS, EVELEIGH DE. Selective Screening Methods for the Isolation of High Yielding Cellulase Mutants of Trichoderma reesei. Hydrolys Cellul Mech Enzym Acid Catal. 1979. p. 289-301.

6. Kawamori M, Morikawa Y, Takasawa S. Induction and production of cellulases by L-sorbose in Trichoderma reesei. Appl Microbiol. 1986;24:449-53.

7. Shida Y, Yamaguchi K, Nitta M, Nakamura A, Takahashi M, Kidokoro SI, et al. The impact of a singlenucleotide mutation of bgl2 on cellulase induction in a Trichoderma reesei mutant. Biotechnol Biofuels. BioMed Central; 2015;8:1-18.

8. De Oliveira Porciuncula J, Furukawa T, Mori K, Shida Y, Hirakawa H, Tashiro K, et al. Single nucleotide polymorphism analysis of a trichoderma reesei hyper-cellulolytic mutant developed in japan. Biosci Biotechnol Biochem. 2013;77:534-43.

9. Ilmén $M$, Thrane $C$, Penttilä $M$. The glucose repressor genecre1 ofTrichoderma: Isolation and expression of a full-length and a truncated mutant form. Mol. Gen. Genet. MGG. 1996. p. 451-60.

10. Adnan M, Zheng W, Islam W, Arif M, Abubakar YS, Wang Z, et al. Carbon catabolite repression in filamentous Fungi. Int J Mol Sci. 2018;19:1-23.

11. Cziferszky A, Mach RL, Kubicek CP. Phosphorylation positively regulates DNA binding of the carbon catabolite repressor Cre1 of Hypocrea jecorina (Trichoderma reesei). J Biol Chem. 2002;277:1468894.

12. Campos Antoniêto AC, Graciano de Paula R, Santos Castro L dos, Silva-Rocha R, Felix Persinoti G, Nascimento Silva R. Trichoderma reesei CRE1-mediated Carbon Catabolite Repression in Response to Sophorose Through RNA Sequencing Analysis. Curr Genomics. 2015;17:119-31.

13. Baba Y, Sumitani J ichi, Tani S, Kawaguchi T. Characterization of Aspergillus aculeatus $\beta-$ glucosidase 1 accelerating cellulose hydrolysis with Trichoderma cellulase system. AMB Express. 2015;5:0-8. 
14. Nakazawa H, Kawai T, Ida N, Shida Y, Shioya K, Kobayashi Y, et al. A high performance Trichoderma reesei strain that reveals the importance of xylanase III in cellulosic biomass conversion. Enzyme Microb Technol. 2016;82:89-95.

15. Shibata N, Kakeshita H, Igarashi K, Takimura Y, Shida Y, Ogasawara W, et al. Disruption of alphatubulin releases carbon catabolite repression and enhances enzyme production in Trichoderma reesei even in the presence of glucose. Biotechnol Biofuels. 2021;14:1-16.

16. Mandels M, Reese ET. Induction of cellulase in fungi by cellobiose. J Bacteriol. 1960;79:816-26.

17. Mandels M, Parrish FW, Reese ET. Sophorose as an inducer of cellulase in Trichoderma viride. J Bacteriol. 1962;83:400-8.

18. Sternberg D, Mandels GR. Induction of cellulolytic enzymes in Trichoderma reesei by sophorose. J Bacteriol. 1979;139:761-9.

19. Morikawa Y, Ohashi T, Mantani O, Okada H. Cellulase induction by lactose in Trichoderma reesei PC3-7. Appl Microbiol Biotechnol. 1995;44:106-11.

20. Li Y, Liu C, Bai F, Zhao X. Overproduction of cellulase by Trichoderma reesei RUT C30 through batchfeeding of synthesized low-cost sugar mixture. Bioresour Technol. 2016;216:503-10.

21. Nitta M, Furukawa T, Shida Y, Mori K, Kuhara S, Morikawa Y, et al. A new Zn(II) 2Cys 6-type transcription factor BgIR regulates $\beta$-glucosidase expression in Trichoderma reesei. Fungal Genet Biol. 2012;49:388-97.

22. Aro N, Ilmén M, Saloheimo A, Penttilä M. ACEl of Trichoderma reesei is a repressor of cellulase and xylanase expression. Appl Environ Microbiol. 2003;69:56-65.

23. Cao Y, Zheng F, Wang L, Zhao G, Chen G, Zhang W, et al. Rce1, a novel transcriptional repressor, regulates cellulase gene expression by antagonizing the transactivator Xyr1 in Trichoderma reesei. Mol Microbiol. 2017;105:65-83.

24. Wang L, Lv X, Cao Y, Zheng F, Meng X, Shen Y, et al. A novel transcriptional regulator RXE1 modulates the essential transactivator XYR1 and cellulase gene expression in Trichoderma reesei. Appl Microbiol Biotechnol. Applied Microbiology and Biotechnology; 2019;103:4511-23.

25. Meng QS, Zhang F, Liu CG, Zhao XQ, Bai FW. Identification of a novel repressor encoded by the putative gene ctf 1 for cellulase biosynthesis in Trichoderma reesei through artificial zinc finger engineering. Biotechnol Bioeng. 2020;117:1747-60.

26. Stricker AR, Grosstessner-Hain K, Würleitner E, Mach RL. Xyr1 (Xylanase Regulator 1) regulates both the hydrolytic enzyme system and D-xylose metabolism in Hypocrea jecorina. Eukaryot Cell. 2006;5:2128-37.

27. Lichius A, Bidard F, Buchholz F, Le Crom S, Martin J, Schackwitz W, et al. Genome sequencing of the Trichoderma reesei QM9136 mutant identifies a truncation of the transcriptional regulator XYR1 as the cause for its cellulase-negative phenotype. BMC Genomics. 2015;16:1-20.

28. Mach-Aigner AR, Pucher ME, Steiger MG, Bauer GE, Preis SJ, Mach RL. Transcriptional regulation of $x y r 1$, encoding the main regulator of the xylanolytic and cellulolytic enzyme system in Hypocrea jecorina. Appl Environ Microbiol. 2008;74:6554-62. 
29. Fischer J, Schroeckh V, Brakhage AA. Awakening of Fungal Secondary Metabolite Gene Clusters. 2016.

30. Derntl C, Gudynaite-Savitch L, Calixte S, White T, MacH RL, MacH-Aigner AR. Mutation of the Xylanase regulator 1 causes a glucose blind hydrolase expressing phenotype in industrially used Trichoderma strains. Biotechnol Biofuels. 2013;6:1-11.

31. Ellilä S, Fonseca L, Uchima C, Cota J, Goldman GH, Saloheimo M, et al. Development of a low-cost cellulase production process using Trichoderma reesei for Brazilian biorefineries. Biotechnol Biofuels. 2017;10:1-17.

32. Fonseca LM, Parreiras LS, Murakami MT. Rational engineering of the Trichoderma reesei RUT-C30 strain into an industrially relevant platform for cellulase production. Biotechnol Biofuels. 2020;13:115.

33. Hasper AA, Trindade LM, van der Veen D, van Ooyen AJJ, de Graaff LH. Functional analysis of the transcriptional activator XInR from Aspergillus niger. Microbiology. 2004;150:1367-75.

34. Aro N, Saloheimo A, Ilmén M, Penttilä M. ACEll, a Novel Transcriptional Activator Involved in Regulation of Cellulase and Xvlanase Genes of Trichoderma reesei. J Biol Chem. 2001;276:2430914.

35. Stricker AR, Trefflinger P, Aro N, Penttilä M, Mach RL. Role of Ace2 (Activator of Cellulases 2) within the xyn2 transcriptosome of Hypocrea jecorina. Fungal Genet Biol. 2008;45:436-45.

36. Mari Häkkinen, Mari J Valkonen, Ann Westerholm-Parvinen, Nina Aro, Mikko Arvas, Marika Vitikainen, Merja Penttilä MS\& TMP. Screening of candidate regulators for cellulase and hemicellulase production in Trichoderma reesei and identification of a factor essential for cellulase production. Biotechnol Biofuels. 2014;7.

37. Zhang J, Chen Y, Wu C, Liu P, Wang W, Wei D. The transcription factor ACE3 controls cellulase activities and lactose metabolism via two additional regulators in the fungus Trichoderma reesei. $\mathrm{J}$ Biol Chem. 2019;294:18435-50.

38. Ivanova C, Bååth JA, Seiboth B, Kubicek CP. Systems Analysis of Lactose Metabolism in Trichoderma reesei Identifies a Lactose Permease That Is Essential for Cellulase Induction. PLoS One. 2013;8:1-10.

39. Zhang W, Kou Y, Xu J, Cao Y, Zhao G, Shao J, et al. Two major facilitator superfamily sugar transporters from Trichoderma reesei and their roles in induction of cellulase biosynthesis. J Biol Chem. 2013;288:32861-72.

40. Havukainen S, Valkonen M, Koivuranta K, Landowski CP. Studies on sugar transporter CRT1 reveal new characteristics that are critical for cellulase induction in Trichoderma reesei. Biotechnol Biofuels. 2020;13:1-20.

41. Ivanova C, Ramoni J, Aouam T, Frischmann A, Seiboth B, Baker SE, et al. Genome sequencing and transcriptome analysis of Trichoderma reesei QM9978 strain reveals a distal chromosome translocation to be responsible for loss of vib1 expression and loss of cellulase induction. Biotechnol Biofuels. 2017;10:1-15. 
42. Zhang F, Zhao X, Bai F. Improvement of cellulase production in Trichoderma reesei Rut-C30 by overexpression of a novel regulatory gene Trvib-1. Bioresour Technol. 2018;247:676-83.

43. Xiong Y, Sun J, Glass NL. VIB1, a Link between Glucose Signaling and Carbon Catabolite Repression, Is Essential for Plant Cell Wall Degradation by Neurospora crassa. PLoS Genet. 2014;10.

44. Chen X, Song B, Liu M, Qin L, Dong Z. Understanding the Role of Trichoderma reesei Vib1 in Gene Expression during Cellulose Degradation. J Fungi. 2021;7:613.

45. Zheng F, Yang R, Cao Y, Zhang W, Lv X, Meng X, et al. Engineering Trichoderma reesei for Hyperproduction of Cellulases on Glucose to Efficiently Saccharify Pretreated Corncobs. J Agric Food Chem. 2020; 68:12671-82

46. Dos Santos Castro L, De Paula RG, Antoniêto ACC, Persinoti GF, Silva-Rocha R, Silva RN. Understanding the role of the master regulator XYR1 in Trichoderma reesei by global transcriptional analysis. Front Microbiol. 2016;7:1-16.

47. Sheir-Neiss G, Montenecourt BS. Characterization of the secreted cellulases of Trichoderma reesei wild type and mutants during controlled fermentations. Appl Microbiol Biotechnol. 1984;20:46-53.

48. Chen Y, Wu C, Fan X, Zhao X, Zhao X, Shen T, et al. Engineering of Trichoderma reesei for enhanced degradation of lignocellulosic biomass by truncation of the cellulase activator ACE3. Biotechnol Biofuels. 2020;13:1-14.

49. Luo Y, Valkonen M, Jackson RE, Palmer JM, Bhalla A, Nikolaev I, et al. Modification of transcriptional factor ACE3 enhances protein production in Trichoderma reesei in the absence of cellulase gene inducer. Biotechnol Biofuels. 2020;13:1-16.

50. Xue Y, Han J, Li Y, Liu J, Gan L, Long M. Promoting cellulase and hemicellulase production from Trichoderma orientalis EU7-22 by overexpression of transcription factors Xyr1 and Ace3. Bioresour Technol. 2020;296:122355.

51. T. G. Watson, Nelligan I, Lessing L. Cellulase production by Trichoderma reesei (RUT-C30) in fedbatch culture. Biotechnol Lett. 1984;6:667-72.

52. Jourdier E, Cohen C, Poughon L, Larroche C, Monot F, Chaabane F Ben. Cellulase activity mapping of Trichoderma reesei cultivated in sugar mixtures under fed-batch conditions. Biotechnol Biofuels. 2013;6.

53. Nevalainen H, Peterson R. Heterologous Expression of Proteins in Trichoderma. New Futur Dev Microb Biotechnol Bioeng Aspergillus Syst Prop Appl. 2016. p. 89-102.

54. Rantasalo A, Vitikainen M, Paasikallio T, Jäntti J, Landowski CP, Mojzita D. Novel genetic tools that enable highly pure protein production in Trichoderma reesei. Sci Rep. 2019;9:1-12.

55. Zhang J, Wu C, Wang W, Wang W, Wei D. A versatile Trichoderma reesei expression system for the production of heterologous proteins. Biotechnol Lett.; 2018;40:965-72.

56. MerjaPenttilä, HelenaNevalainen, MarjaanaRättö, ElinaSalminen, JonathanKnowles. A versatile transformation system for the cellulolytic filamentous fungus Trichoderma reesei. Gene. 1987;61:155-64. 


\section{Figures}
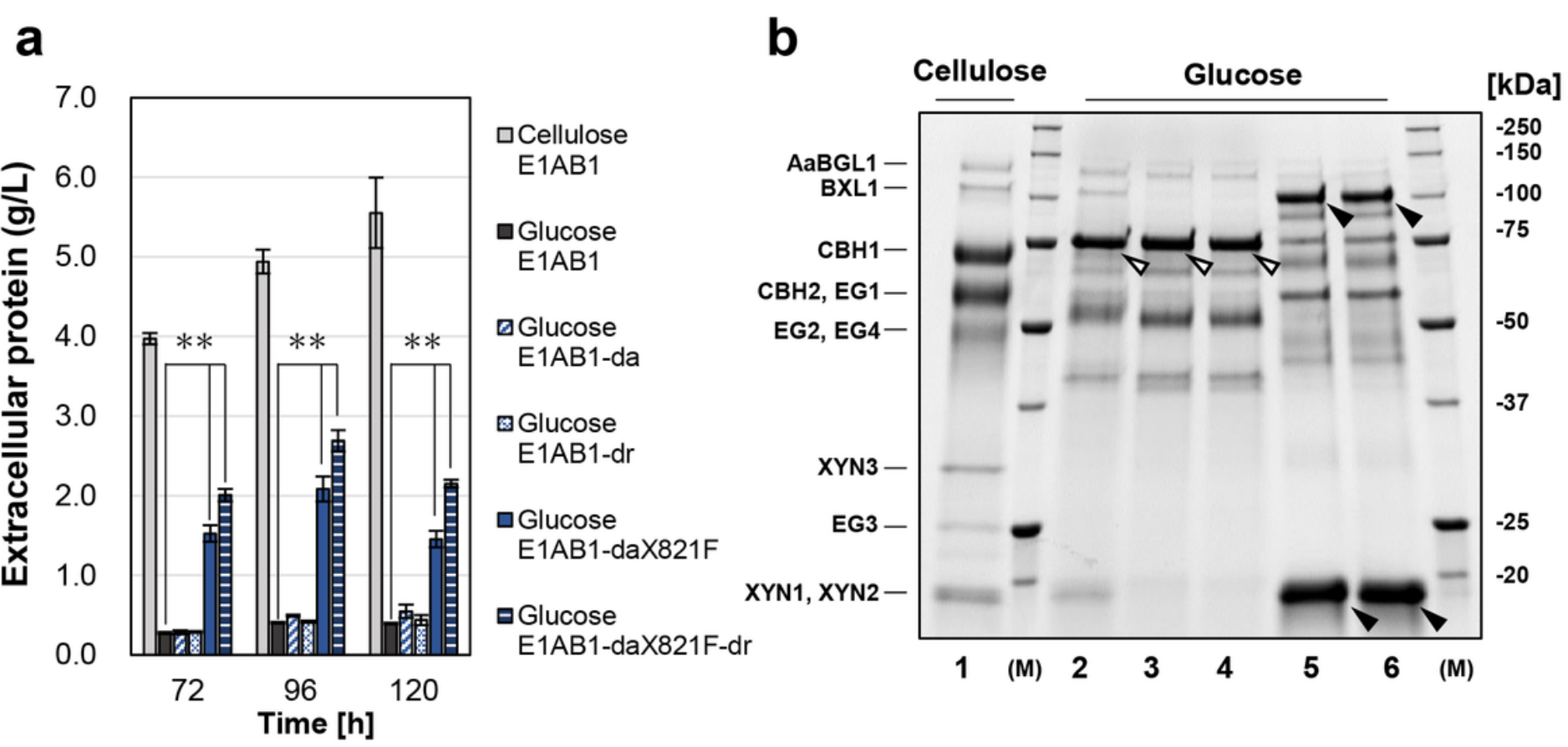

Figure 1

Effects of constitutive expression of V821F mutated Xyr1 and disruption of repressors on glucose culture. a Extracellular protein from the cultivation of samples after 72, 96, and $120 \mathrm{~h}$. Trichoderma reesei strain E1AB1 was cultivated in shake flasks on an inducing medium containing $3 \%$ cellulose, and recombinant strains E1AB1-da ( $\triangle$ Ace1), E1AB1-dr ( $\triangle$ Rce1), E1AB1-daX821F ( $\triangle$ Ace1-Pact1-Xyr1 ${ }^{\text {V21F }}$ ), and E1AB1-

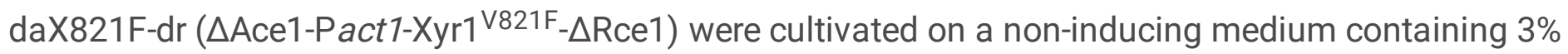
glucose. $\mathbf{b}$ Sodium dodecyl sulfate-polyacrylamide gel electrophoresis analysis of the secreted proteins after $72 \mathrm{~h}$. T. reesei strain E1AB1 with 3\% cellulose (lane 1) and 3\% glucose (lane 2) cultures, and recombinant strains E1AB1-da ( $\triangle A$ ce1, lane 3), E1AB1-dr ( $\triangle$ Rce1, lane 4), E1AB1-daX821F ( $\triangle$ Ace1-Pact1$\mathrm{Xyr}^{\mathrm{V} 821 \mathrm{~F}}$, lane 5), and E1AB1-daX821F-dr ( $\triangle \mathrm{Ace} 1$-Pact1-Xyr1 V821F- $\Delta$ Rce1, lane 6) with $3 \%$ glucose cultures. Open arrowhead indicates the unknown protein confirmed in glucose culture (lanes 2-4). Closed arrowheads indicate clearly overexpressed proteins, likely corresponding to the main hemicellulase enzymes (BXL1, XYN1, XYN2, lanes 5 and 6). Error bars indicate standard deviations. Statistical significance was determined by a two-tailed unpaired Student's $t$-test. ${ }^{* *} p<0.01$. 
a

b
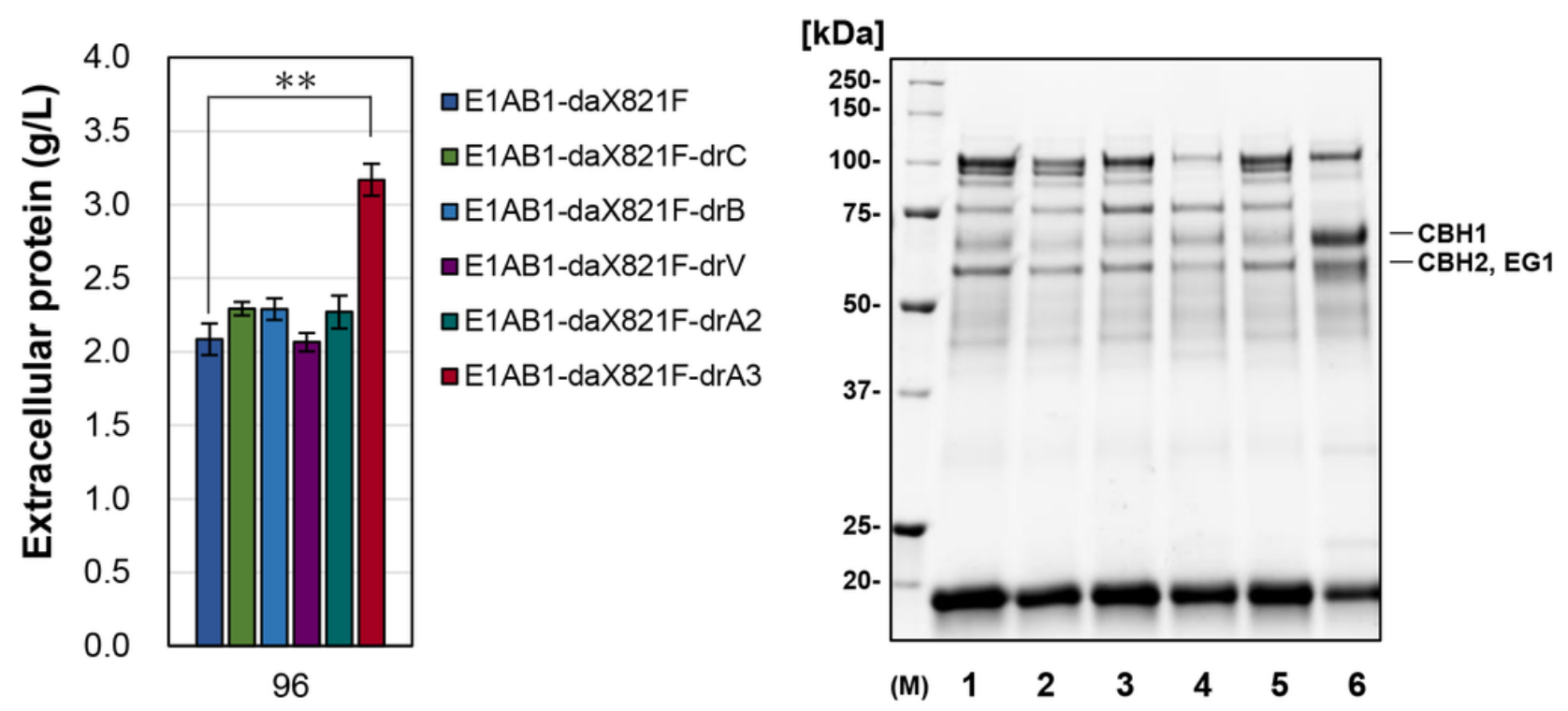

Time [h]

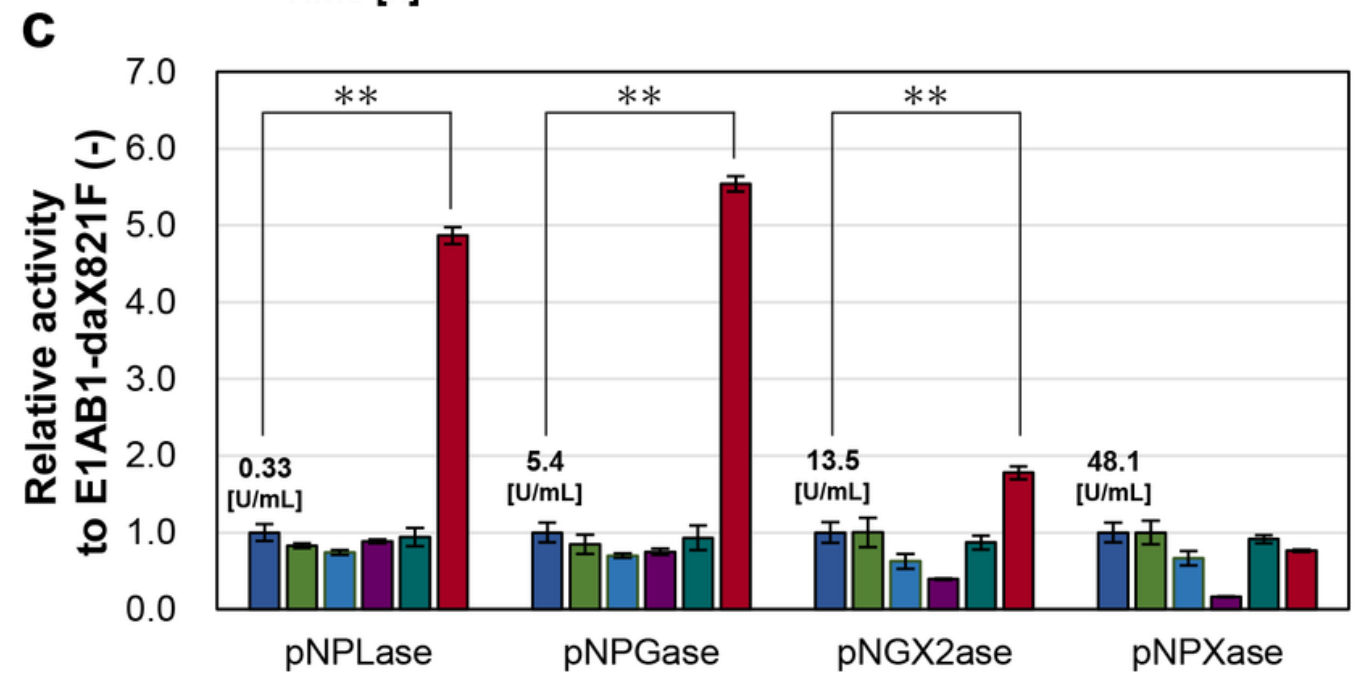

-E1AB1-daX821F 口E1AB1-daX821F-drC -E1AB1-daX821F-drB -E1AB1-daX821F-drV -E1AB1-daX821F-drA2 aE1AB1-daX821F-drA3

Figure 2

Co-expression of factors involved in cellulase transcription in the E1AB1-daX821F strain. Trichoderma reesei strain E1AB1-daX821F was co-expressed with various factors that relate to cellulase expression and cultivated in shake flasks on a non-inducing medium containing $3 \%$ glucose. a Extracellular protein from cultivation samples after 96 h. b Sodium dodecyl sulphate-polyacrylamide gel electrophoresis analysis of the secreted proteins after $72 \mathrm{~h}$ in a glucose culture of T. reesei E1AB1-daX821F (lane 1, as control), E1AB1-daX821F-drC (lane 2, Xyr1 ${ }^{\mathrm{V} 821 \mathrm{~F}}$ and Crt1), E1AB1-daX821F-drB (lane 3, Xyr1 ${ }^{\mathrm{V} 821 \mathrm{~F}}$ and BgIR), E1AB1-daX821F-drV (lane 4, Xyr1 ${ }^{\text {V821F }}$ and Vib1), E1AB1-daX821F-drA2 (lane 5, Xyr1 ${ }^{\text {V821F }}$ and Ace2), and E1AB1-daX821F-drA3 (lane 6, Xyr1 ${ }^{\mathrm{V} 821 \mathrm{~F}}$ and Ace3. c Enzyme activity profile of the samples after $72 \mathrm{~h}$. One unit of activity is defined as the amount of enzyme that produced $1 \mu \mathrm{mol}$ of $p$-nitrophenol 
per minute per $\mathrm{mL}$ of culture supernatant from the substrate at $50{ }^{\circ} \mathrm{C}$. Bar graphs show the activity relative to that of E1AB1-daX821F. Error bars indicate standard deviations. Statistical significance was determined by the two-tailed unpaired Student's $t$-test. ${ }^{*} p<0.01$

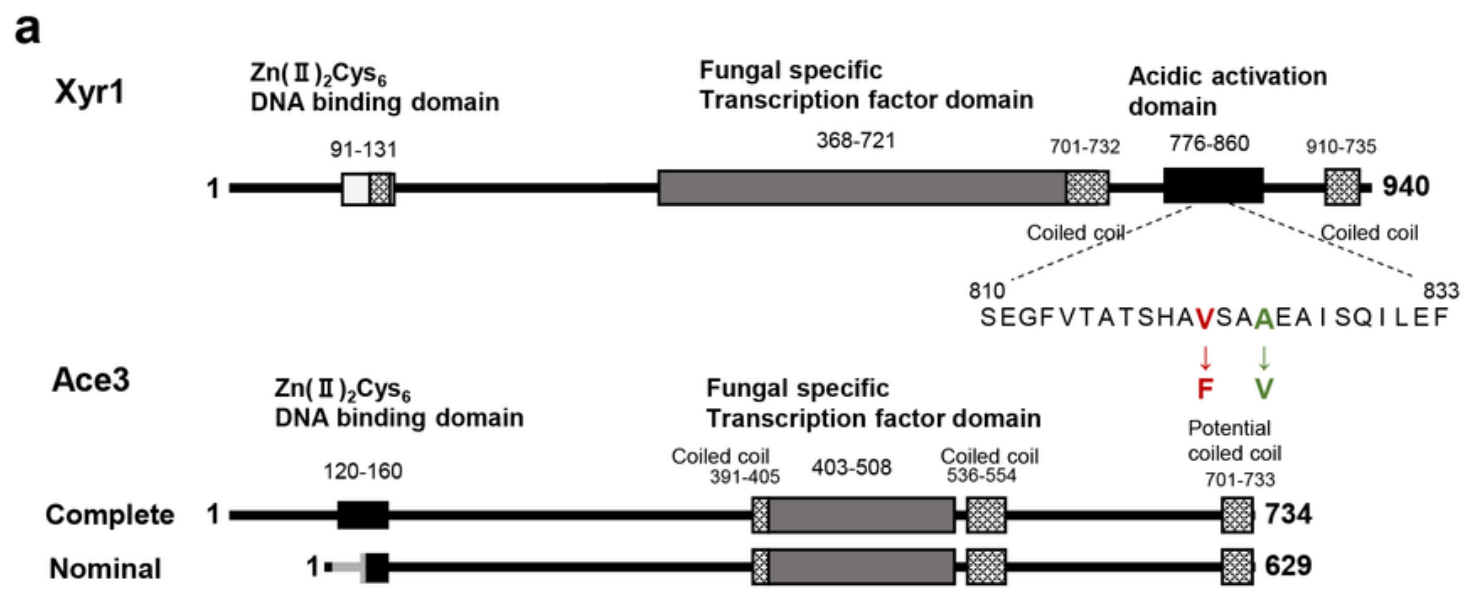

b

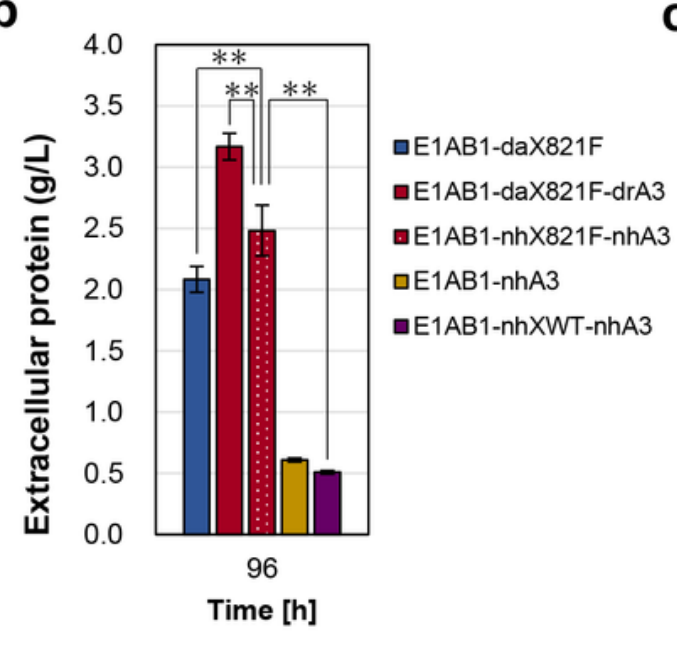

d

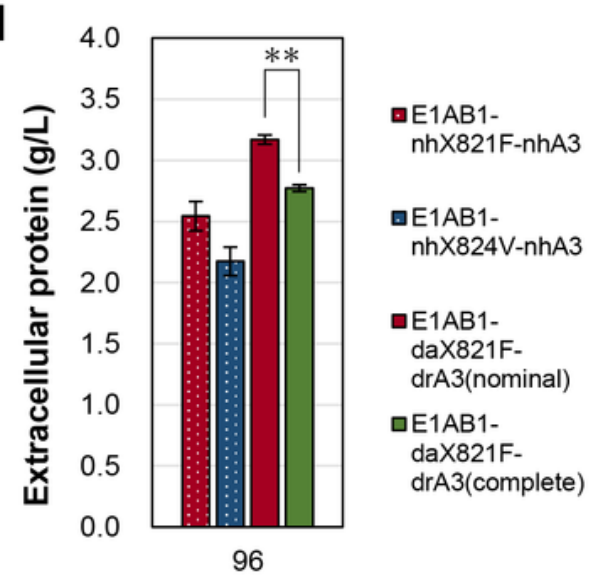

Time [h]
C [kDa]

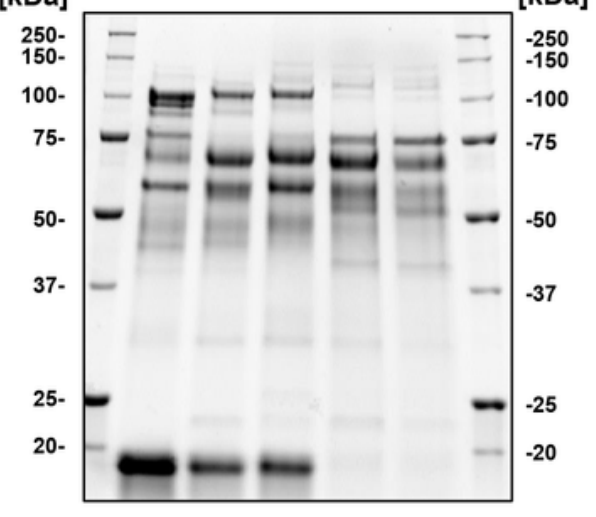

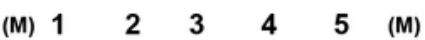

e

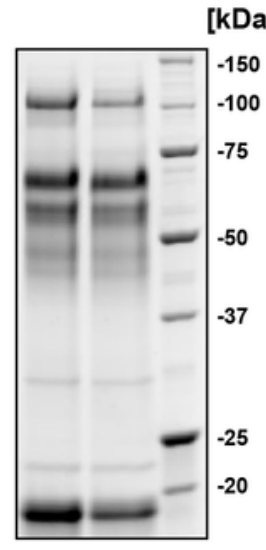

12 (M)

[kDa]

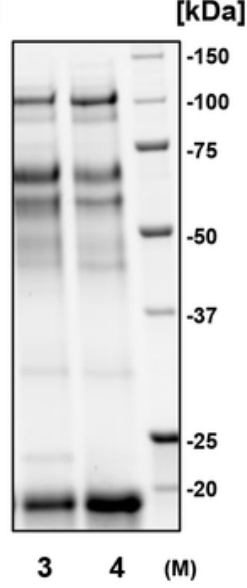

Figure 3 
Gene combination requirements for inducer-free cellulase production. a Putative domain region of Xyr1 and Ace3. Strains with an altered gene insertion locus, Ace3 alone and in combination with wild-type Xyr1, mutation of V821F or A824V, and complete or nominal Ace 3 and $\mathrm{Xyr}^{\mathrm{V} 821 \mathrm{~F}}$ were cultivated in shake flasks on a non-inducing medium comprising $3 \%$ glucose. $\mathbf{b}$, $\mathbf{d}$ Extracellular protein from cultivation samples after $96 \mathrm{~h}$. c Sodium dodecyl sulfate-polyacrylamide gel electrophoresis (SDS-PAGE) analysis of secreted proteins after $72 \mathrm{~h}$ in a glucose culture of Trichoderma reesei E1AB1-daX821F (lane 1, as control), E1AB1-daX821F-drA3 (lane 2, as control), E1AB1-nhX821F-nhA3 (lane 3, Xyr1 ${ }^{\text {V821F }}$ and nominal Ace3 with non-homologous recombination), E1AB1-nhA3 (lane 4, nominal Ace3 only with nonhomologous recombination), and E1AB1-nhXWT-nhA3 (lane 5, Xyr1 ${ }^{\text {WT }}$ and nominal Ace3 with nonhomologous recombination). e SDS-PAGE analysis of secreted proteins after $72 \mathrm{~h}$ in a glucose culture of Trichoderma reeseiE1AB1-nhX821 F-nhA3 (lane 1, Xyr1 ${ }^{\mathrm{V} 821 \mathrm{~F}}$ and nominal Ace3 with non-homologous recombination), E1AB1-nhX824V-nhA3 (lane 2, Xyr1 ${ }^{\mathrm{A} 824 \mathrm{~V}}$ and nominal Ace3 with non-homologous recombination), E1AB1-daX821F-drA3 (nominal) (lane 3, Xyr1 ${ }^{\mathrm{V} 821 \mathrm{~F}}$ and nominal Ace3), and E1AB1daX821F-drA3 (complete) (lane 4, Xyr $1^{\mathrm{V} 821 \mathrm{~F}}$ and complete Ace3). Error bars indicate standard deviations. Statistical significance was determined by a two-tailed unpaired Student's $t$-test. ${ }^{* *} p<0.01$. 
a

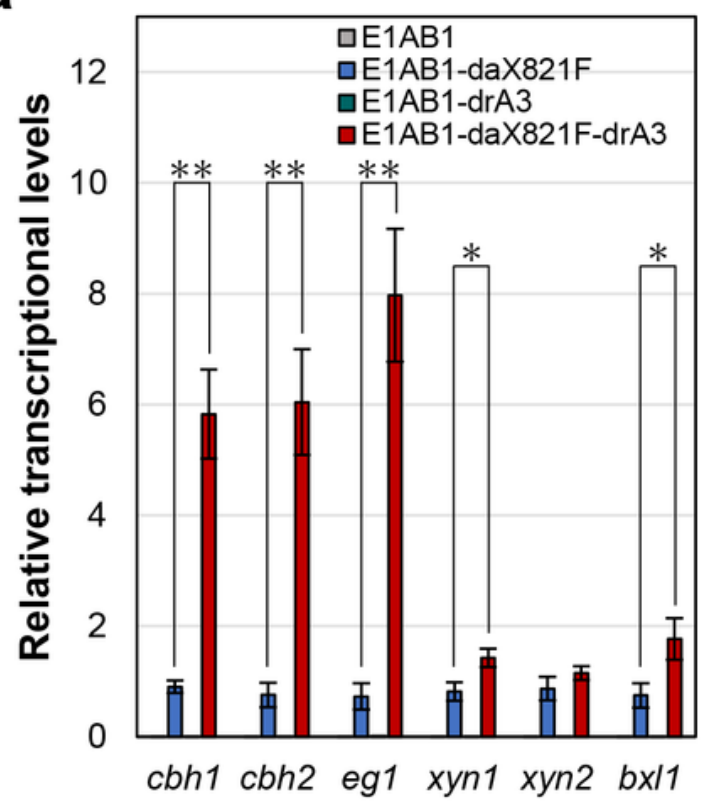

C

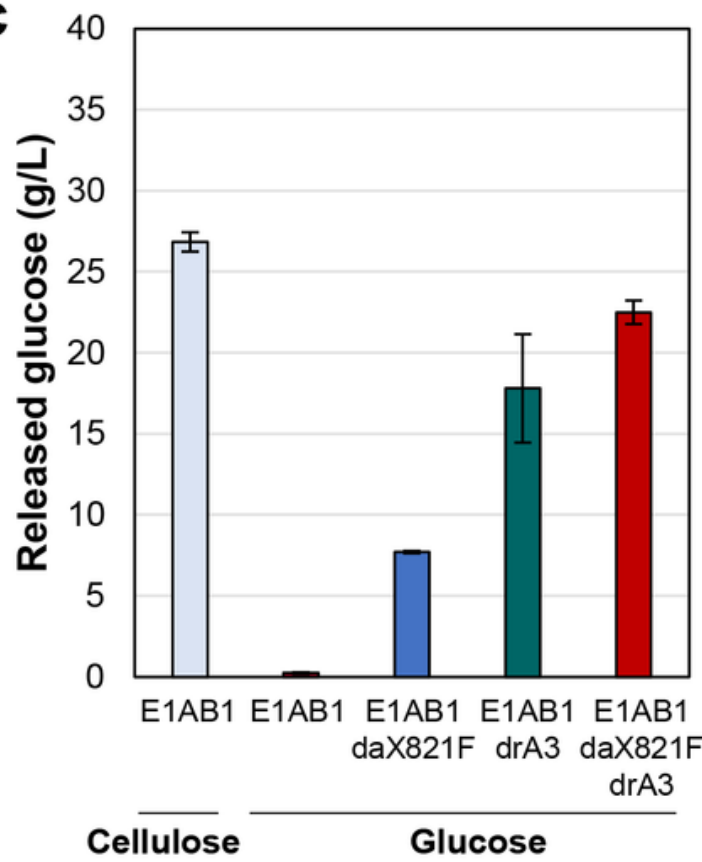

b

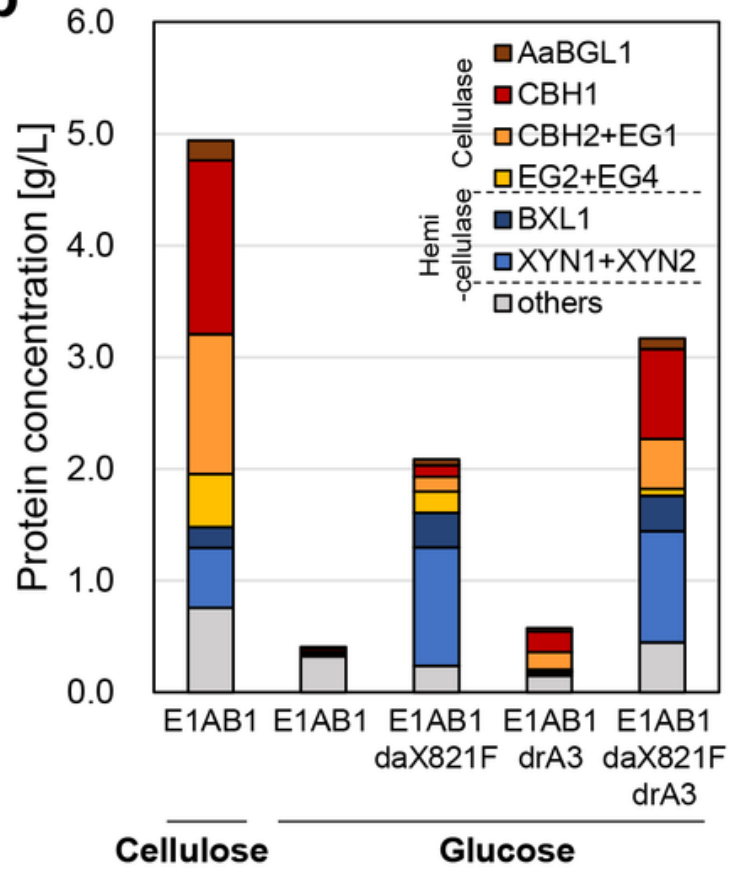

d

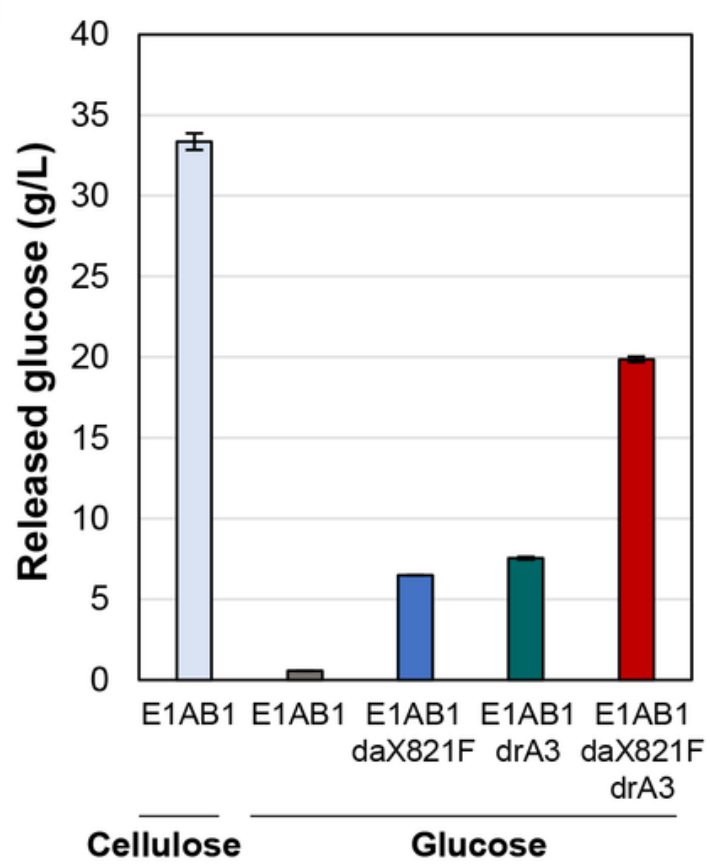

Figure 4

Analysis of gene expression, enzyme composition, and evaluation of saccharification activity of microcrystalline cellulose. a Relative gene expression of the major cellulases and hemicellulases. The real-time polymerase chain reaction was performed on the samples taken after $48 \mathrm{~h}$. The transcriptional levels of pgk1 and E1AB1-daX821F strain RNA were measured for reference calculation and data normalization, respectively, and analyzed using the $\Delta \Delta$ Ct method. b Enzyme concentration was 
calculated from the enzyme composition and protein concentration. The composition ratios were calculated from the band patterns following sodium dodecyl sulphate-polyacrylamide gel electrophoresis (see Additional file 1) derived from strains E1AB1 (cellulose and glucose culture), E1AB1-daX821F (glucose culture), E1AB1-drA3 (glucose culture), and E1AB1-daX821F-drA3 (glucose culture). Protein concentrations were determined from the $96 \mathrm{~h}$ values in Figure $S 1$ (see Additional file 1). c Microcrystalline cellulose saccharification using the same protein dosage (2.0 $\mathrm{mg}$ protein/g cellulose). $\mathbf{d}$ Microcrystalline cellulose saccharification using the same volume of culture supernatant $(0.87 \mathrm{~mL}$ culture supernatant/g cellulose). Error bars indicate standard deviations. Statistical significance was determined by a two-tailed unpaired Student's $t$-test. ${ }^{*} p<0.01,{ }^{*} p<0.05$.

\section{Supplementary Files}

This is a list of supplementary files associated with this preprint. Click to download.

- Additionalfile1FigureS1.pptx

- Additionalfile2FigureS2.pptx

- Additionalfile3FigureS3.pptx

- Additionalfile4TableS1.xlsx

- Additionalfile5TableS2.xIsx

- Additionalfile6TableS3.xlsx 